Review Article

\title{
Mitochondrial Dysfunctions: A Thread Sewing Together Alzheimer's Disease, Diabetes, and Obesity
}

\author{
Giulia Rigotto ${ }^{1}$ and Emy Basso $\mathbb{D}^{1,2}$ \\ ${ }^{1}$ Department of Biomedical Sciences, University of Padua, 35131 Padua, Italy \\ ${ }^{2}$ National Research Council, Department of Biomedical Science, Neuroscience Institute (Padua Section), 35131 Padua, Italy \\ Correspondence should be addressed to Emy Basso; emy.basso@cnr.it
}

Received 25 January 2019; Revised 20 April 2019; Accepted 21 May 2019; Published 16 June 2019

Guest Editor: Ulrike Hendgen-Cotta

Copyright (c) 2019 Giulia Rigotto and Emy Basso. This is an open access article distributed under the Creative Commons Attribution License, which permits unrestricted use, distribution, and reproduction in any medium, provided the original work is properly cited.

\begin{abstract}
Metabolic disorders are severe and chronic impairments of the health of many people and represent a challenge for the society as a whole that has to deal with an ever-increasing number of affected individuals. Among common metabolic disorders are Alzheimer's disease, obesity, and type 2 diabetes. These disorders do not have a univocal genetic cause but rather can result from the interaction of multiple genes, lifestyle, and environmental factors. Mitochondrial alterations have emerged as a feature common to all these disorders, underlining perhaps an impaired coordination between cellular needs and mitochondrial responses that could contribute to their development and/or progression.
\end{abstract}

\section{Introduction}

Obesity, diabetes, and Alzheimer's disease (AD) are longterm pathologies affecting millions of individuals in the developed countries and progressively expanding also in developing countries. Moreover, obesity and diabetes have long been considered significant risk factors for the progression of late onset Alzheimer's disease, and in recent years, a growing number of epidemiological studies are finding compelling connections between these complex metabolic disorders $[1,2]$. A coordinated approach to characterize common, shared traits would be helpful to better understand these conditions and, hopefully, devise prevention strategies. There are several important and recognized intersections among these disorders that point to common pathological developments, but also possibly common, impaired metabolic pathways. One such trait is insulin resistance which commonly occurs in peripheral tissues in obesity and diabetes, but has been also shown to occur in the brain of Alzheimer's disease patients $[3,4]$. The canonical function of insulin is the regulation of body metabolism, but it has as well a role in promoting synaptic and neuronal plasticity which are greatly compromised in $\mathrm{AD}[5,6]$. Dysregulated lipid metabolism is common in obesity and diabetes; the increased levels of free fatty acids (FFA) in the bloodstream can inhibit the antilipolytic action of insulin and alter the permeability of the blood brain barrier (BBB) resulting in FFA infiltrating in the brain and contributing to brain damage and declining cognitive functions $[7,8]$.

Another common trait is the presence of advanced glycation end products (AGEs) found in both diabetic and $\mathrm{AD}$ patients $[9,10]$; long standing, elevated glucose plasma levels promote the formation of covalent adducts with proteins through a nonenzymatic reaction called glycation. AGE products alter the structure and function of biological molecules and increase oxidative stress promoting intracellular damage and apoptosis [11]. AGE products bind to the multiligand transmembrane receptor for advanced glycation end products (RAGE), and this interaction results in the activation of downstream signaling pathways including the activation of NF- $\kappa \mathrm{B}$ transcription factor and the triggering of proinflammatory responses [12]. It has also been reported that RAGE promotes $A \beta$ peptide production [13] with consequences on the integrity of the BBB [14].

Inflammation is another common feature of these disorders. Obese patients display low-grade chronic inflammation 
in the adipose tissue characterized by the infiltration of inflammatory cells and the increased production and secretion of proinflammatory factors $[15,16]$. High levels of FFA introduced with the diet can trigger an inflammatory cascade initiated by Toll-like receptor 4 (TLR4) and the release of proinflammatory cytokines such as TNF- $\alpha$ and interleukins IL-1 $\beta$ and IL-6 [17]. The pathogenesis of diabetes is as well associated with high immune system activation [18], and inflammation is the main cause of diabetes complications such as retinopathy, nephropathy, and neuropathy. It is known that chronic hyperglycemia activates NF- $\kappa$ B and stimulates the release of proinflammatory cytokines [19]. The effects of NF- $\kappa \mathrm{B}$-mediated metabolic inflammation are deleterious and can result in impairments of intracellular signaling and disruptions of metabolic physiology. Neuroinflammation has been known for many years to occur in $\mathrm{AD}$ : glial cell activation is observed in the proximity of the lesions [20]; moreover, preclinical genetic data have shown that the activation of the immune system contributes to the pathogenesis of the disease [21-23].

Of course, the key issue is to understand how mostly peripheral metabolic impairments observed in obesity and diabetes might be connected with cerebral pathological alterations present in $\mathrm{AD}$.

Mitochondria perform a number of essential activities for cellular/tissue differentiation and survival ranging from ATP production to reactive oxygen species (ROS) signaling, catabolism of fatty acid, ion homeostasis, biosynthesis of heme, and cell death. Because of this central role played in cell metabolism, it is not surprising that mitochondrial malfunctioning has been linked to various different metabolic disorders as different as type 2 diabetes [24], cancer [25], and neurodegenerative disorders $[26,27]$.

Mitochondrial dysfunction is a broad term that comprises maladaptive physiological responses such as impaired substrate catabolism, dysregulated $\mathrm{Ca}^{2+}$ buffering, compromised iron transport, and changes in mitochondrial dynamics, and these could translate into insufficient ATP production, increased ROS, and cell death. Mitochondrial dysfunctions can be secondary events or consequences of altered metabolic pathways: the cause of inflammation affecting adipose tissue in obesity is not clear, but it is known that mitochondria are important for maintaining metabolic homeostasis in white adipocytes $[28,29]$, and it is known that an excessive substrate availability affects mitochondrial functions [30-32]. Dyslipidemia and increased concentration of long-chain fatty acids could induce oxidative stress and mitochondrial dysfunction [33]; increased production of toxic $A \beta$ oligomers has been shown to impair mitochondria in $\mathrm{AD}$ [34]. But mitochondrial dysfunctions could represent early events in the development of a pathology: in a number of studies, mitochondrial inheritance has been associated with obesity and type 2 diabetes, as well as metabolic syndrome, insulin resistance, and cardiovascular disease [35-37]. A recent study has found an interesting genetic association of mitochondrial, nuclear mitochondrial variants and genes with seven metabolic traits comprising body mass index, waisthip-ratio, fasting glucose, fasting insulin [38]: traits characteristic of cardiovascular disorders, obesity, diabetes, and neurodegeneration. These findings point to a subtler role of the mitochondria in the development and possible origin of complex metabolic disorders and make worth investigation of possible connections among the mitochondria, metabolism, and complex metabolic disorders.

\section{Mitochondria Structure and Functions}

Mitochondria originated from the endosymbiosis established between an alpha-proteobacterium and a prokaryote cell [39-41] that took place only once in eukaryotic evolution [42]. It is commonly believed that the origin of complexity preceded the acquisition of mitochondria [43, 44], but recently, it has been proposed that mitochondria are prerequisite to complexity [45], because oxidative phosphorylation across the wide area of the internal membrane enabled an almost 200,000 fold expansion of the original cellular genome size. The energy necessary to sustain the expression and the working of such a large number of proteins is provided mostly by the mitochondria that, for this purpose, retain a core of genes required for the expression of proteins of the respiratory electron transport chain and of the ATP synthase [46]. The rest of about 1200 proteins present in the mitochondria are encoded by genes present in the nucleus. This peculiar feature makes the mitochondria, and the cell as well, dependent on the coordinated cross talk between two independent genomes, the nuclear and the mitochondrial one, increasing the possibilities of malfunctioning and, for this reason, demanding layers of checkpoint controls. In addition to providing energy for the cell, the mitochondria are essential for signal transduction, cell proliferation, and cell death; this array of important functions makes the regulation of mitochondrial biogenesis vital for proper cellular functioning [47]. The damage of normal mitochondrial dynamics caused by mutations or environmental toxins can result in homeostatic imbalances that can hamper mitochondrial membrane potential and all the functions relying on it, such as ATP production and active transport of proteins and ions across the membrane; also, the fall in energy charge can result in an increase in free radical production and altered mitophagy $[48,49]$. All these events can have direct impact in the development and progression of complex disorders. Figure 1 shows a representative image of detailed mitochondrial morphology.

\section{Membranes and Membrane- Delimited Domains}

Mitochondria possess two separate and functionally distinct membranes, the outer membrane $(\mathrm{OM})$, which separates the inside of the organelle from the rest of the cell and provides the platform for the communication interaction of the mitochondria with other cellular compartments, and the ultra-specialized and highly folded inner membrane (IM). The building blocks of the two membranes are represented mostly by phospholipids, while sterol content is usually low, with the exception of the cells that synthetize steroid hormones $[50,51]$. The most abundant phospholipids are phosphatidylcholine (PC) and phosphatidylethanolamine 


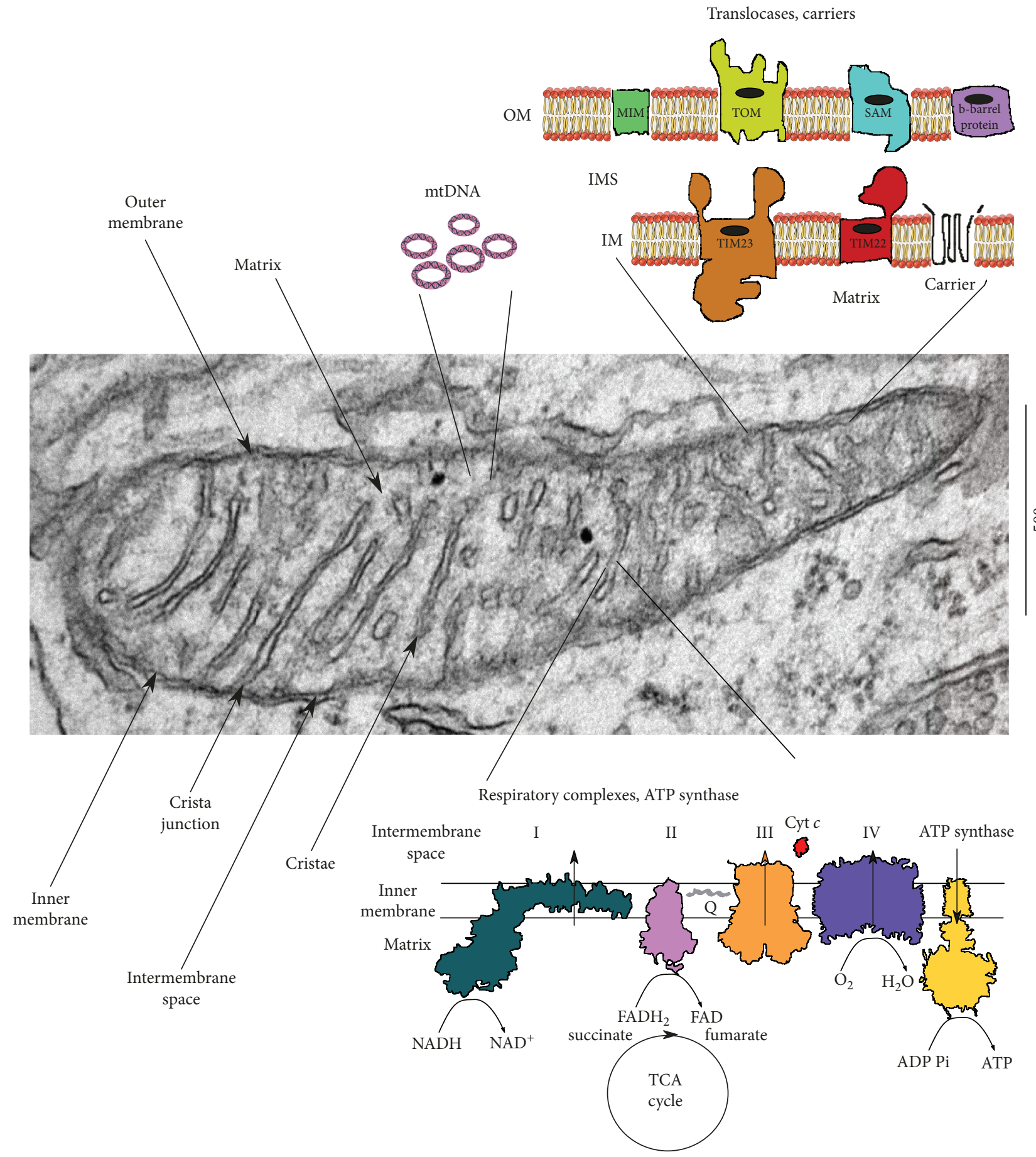

FIGURE 1: Electron micrograph of mouse brain mitochondria, cartoons of some mitochondrial structures, and their localization within the organelles.

(PE), representing respectively about 40 and 30 percent of total phospholipids; the less represented are phosphatidylinositol (PI) and phosphatidylserine (PS), together comprising about 6 percent of total phospholipids [52, 53]. Interestingly, the lipid composition of the OM differs significantly from that of the inner membrane [54, 55]; moreover, phospholipid distribution is not even across the leaflets of the membranes [56, 57]. Both these features point to a specific physiological role for each class of phospholipids.
Cardiolipin (CL) is the signature lipid of the mitochondria, with content in the range of $15-20$ percent, and it is enriched in the IM $[58,59]$; it regulates mitochondria bioenergetics by binding to and influencing the activity of respiratory chain complexes $[60,61]$; furthermore, it also stabilizes the respiratory supercomplexes [62, 63]. Consistent with this function is the observation that CL-deficient mitochondria have a decreased membrane potential [61]. Cardiolipin, as well as cardiolipin remodeling $[64,65]$, is 
fundamental for the structure of the inner membrane and is critical for membrane dynamics, both IM fusion [66, 67] and fission $[68,69]$, via its interaction with mitochondrial proteins OPA1 and Drp1, respectively. In addition, CL has an important role in mitochondria quality control: the externalization of CL to the outer membrane is recognized as a signal for mitophagy, likely through a specific interaction with microtubule-associated protein 1A/1B-light chain 3 (LC3) $[70,71]$.

The outer membrane is critical for the communication and interactions between the mitochondria and the rest of the cell; the passage of small solutes and larger molecules is finely regulated by several channels. Ions and small molecules exchange through the abundant voltage-dependent anion channel (VDAC) [72]. Bigger molecules, especially proteins, are imported via specialized channels, part of large translocase complexes [73]. Tom40, the main protein import channel of the translocase of the outer membrane (TOM), transports numerous proteins presenting positively charged targeting sequences [74]; Sam50 of the sorting and assembly machinery (SAM) inserts $\beta$-barrel precursor proteins into the outer membrane $[75,76]$. Yeasts also possess Mdm10, the mitochondrial distribution and morphology protein which, together with its role in the sorting and assembly machinery [77], acts as a membrane anchor of the ER-mitochondrial encounter structure ERMES tethering the ER and mitochondria [78, 79]. Recently, other proteins forming non- $\beta$-barrel channels on the mitochondria outer membrane have been discovered in yeast, suggesting a higher than expected degree of fluxes' regulation at the level of the OM [80].

The IM presents a much more expanded surface than the surrounding OM, because of its largely folded structure. Given its characteristic conformation, it is considered to be composed by two morphologically identifiable subdomains: the portion of the membrane closely apposed to the outer membrane is called the inner boundary domain, while the tubular or lamellar structures that extend into the central mitochondrial compartment are the cristae [81]. The inner boundary membrane is enriched with proteins participating in the transport of ions (i.e., the $\mathrm{Ca}^{2+}$ uniporter; the $\mathrm{Ca}^{2+} / \mathrm{Na}^{+}$exchanger), metabolites (pyruvate carrier, ATP/ADP exchanger), and proteins (the two major complexes are TIM22, the carrier translocase of the inner mitochondrial membrane, and TIM23, the presequence translocase of the inner mitochondrial membrane) [82-84].

The cristae membranes are the main site where oxidative phosphorylation takes place, as they host the fully assembled complexes of the electron transport chain and the ATP synthase. Cristae architecture is quite heterogeneous, depending on the cell type and the energetic state of the mitochondria [85-87].

Cristae are connected to the inner boundary domain by narrow tubular structures of varying length and diameter ranging from 12 to $40 \mathrm{~nm}$ : the crista junctions [88-90]. The hallmark shape of the crista junctions characterized by a high negative curvature of the membrane is produced and maintained by a conserved mitochondrial contact site and crista organizing system (MICOS). Two distinct MICOS subcomplexes have been identified: one, marked by the core component Mic60, is directly involved in the formation of contact sites between the outer and the inner membrane and is thought to stabilize crista junctions via interaction with the outer membrane TOM and SAM complexes $[91,92]$. The second MICOS subcomplex is characterized by the presence of the Mic10 core component which has the ability to oligomerize and bend the IM and is critical for the formation of crista junctions [93, 94].

The crista junctions are thought to represent a barrier for the free movement of soluble proteins and metabolites between the intermembrane and the intracrista space [89].

The intermembrane space (IMS) between the inner and outer membranes possesses an ionic composition similar to the one of the cytosol, but a specific protein content [95]. Some physicochemical properties of the IMS have been reported to differ from the ones of the cytosol. For example, the $\mathrm{pH}$, measured with targeted $\mathrm{pH}$-sensitive GFP, is proved to be slightly more acidic [96]; also, the ratio between reduced and oxidized glutathione is lower, and the IMS compartment at the steady state is more oxidizing than the cytosol [97]. The many functions of this compartment are being defined, clarifying its critical role in the coordination of mitochondrial activities with several cellular processes including the exchange of proteins, lipids, and metal ions between the matrix and the cytosol; the mediation of signaling pathways that regulate respiration and metabolic functions; the regulated initiation of apoptotic cascades; the confinement of reactive oxygen species produced by the respiratory chain; or the control of mitochondrial morphogenesis [98]. The constriction represented by the crista junctions limits the free diffusion of molecules within the IMS and separates this space into two discrete regions. This compartmentalization could serve to optimize mitochondrial performance: the restricted diffusion of protons might improve the efficiency of the respiration-driven ATP synthesis. Also, large amounts of the soluble electron carrier protein cytochrome $c$ are confined within the lumen of the cristae in close proximity to the position where respiratory chain complexes are preferentially found $[99,100]$, and the release of cytochrome $c$ from the crista space during the apoptotic process requires opening of the crista junctions $[101,102]$.

The inner membrane surrounds the innermost mitochondrial compartment: the matrix which is the site of mitochondrial DNA (mtDNA) replication and transcription, of protein synthesis, and where numerous enzymatic reactions take place. These biosynthetic reactions include those of the tricarboxylic acid cycle (TCA) and fatty acid $\beta$-oxidation. The $\mathrm{pH}$ of the matrix is kept at around 8 [103], slightly higher than the cytoplasmic $\mathrm{pH}$ which is around 7 and higher than the intermembrane $\mathrm{pH}$ : this difference in proton concentration is exploited by the ATP synthase to drive the synthesis of the high energy adenosine triphosphate (ATP) molecule.

\section{Respiratory Chain}

The inner membrane hosts the four large complexes of respiratory chains I-IV and the ATP synthase. Complex I, $\mathrm{NADH} /$ ubiquinone oxidoreductase, is the largest respiratory 
complex; the bovine enzyme contains at least 45 subunits and has a molecular mass greater than $900 \mathrm{kDa}$ [104]. It represents the entry point of the electrons $\left(\mathrm{e}^{-}\right)$in the respiratory chain: two $\mathrm{e}^{-}$donated by $\mathrm{NADH}$ are used to reduce membrane soluble ubiquinone to ubiquinol, and the process is coupled with the vectorial transport of four protons across the IMM. So the energy released in the transfer of electrons through complex I, and also complexes III and IV, is not lost to heat; instead, it is used to pump protons across the membrane to build the mitochondrial membrane potential. Complex I consists of two domains, also called "arms": the hydrophobic arm is inserted into the membrane, while the hydrophilic arm protrudes into the matrix. The minimal module of complex I sufficient to catalyze energy transduction is composed of 14 core subunits. In eukaryotes, the 7 core subunits of the membrane arm are encoded by the mitochondrial genome, while the 7 core subunits of the peripheral arm are encoded by the nuclear genome. In addition to the core subunits, complex I of the eukaryotes possesses a large number of accessory subunits $[105,106]$. The reaction of mitochondrial complex I is reversible, and $\mathrm{e}^{-}$can be transferred from ubiquinol back to $\mathrm{NAD}^{+}$at the expenses of the proton motive force. This reaction can cause an increase in superoxide production, which is rapidly dismutated into hydrogen peroxide $\mathrm{H}_{2} \mathrm{O}_{2}$ [107]. An interesting feature of complex $\mathrm{I}$ is that it can assume two different states: active state A and dormant state D [108], characterized by structural rearrangements and different catalytic activities [109, 110]. The A-form is predominant during steady-state aerobic respiration; it catalyzes the fast $\mathrm{NADH}$ :ubiquinone oxidoreductase reaction. In low-oxygen conditions, the A-form can convert to the $\mathrm{D}$-form which has a lower activity and an initial lag phase; the $\mathrm{D}$-form can be reactivated in the presence of $\mathrm{O}_{2}$ and ubiquinone. The A/D transition during ischemia reperfusion episodes has the ability to limit the "burst" of ROS which occurs in the early stage of reperfusion when $\mathrm{O}_{2}$ levels increase and metabolic intermediates are imbalanced [111].

In the mammalian mitochondria, complex II succinate dehydrogenase $(\mathrm{SDH})$ directly reduces coenzyme $\mathrm{Q}$ with $\mathrm{e}^{-}$ donated by the FADH coenzyme. It is both a component of the TCA cycle (it catalyzes the oxidation of succinate to fumarate) and an electron transfer complex, and it is the only component of the respiratory chain encoded exclusively by nuclear genes (only few exceptions are known [112]). It is composed of a flavoprotein which contains the FAD cofactor and an iron-sulfur protein which has three FeS clusters: these form the catalytic subunit; in addition, mammalian complex II has two transmembrane proteins (SDHC and SDHD) [113] that contribute the ubiquinone binding sites. At variance from the other complexes of the respiratory chain, complex II does not pump protons across the IMM. As $\mathrm{SDH}$ lies at the crossroad of two essential pathways, emerging evidences show that both its biosynthesis and function are closely regulated at posttranslational levels to adapt to metabolic demands [114], and its altered regulation has been linked to several diseases $[115,116]$.

Complex III, cytochrome $c$ reductase, comprises 11 subunits; it accepts $\mathrm{e}^{-}$from reduced coenzyme Q (ubiquinol) and transfer them to cytochrome $c$. It is a symmetrical dimer with three conserved core subunits: cytochrome $b$ (cyt b), cytochrome $c_{1}$ (cyt $c_{1}$ ), and the Rieske iron-sulfur protein [117]. cyt $b$ is the only mtDNA-encoded subunit of complex III; it provides the complex with two distinct binding sites for quinone [118]; while the soluble domain of cyt $c_{1}$ provides the site of interaction with cytochrome $c$ [119]. Complex III is another site of ROS production, and it can possibly release ROS both in the IMS and in the matrix [120]. ROS produced by complex III are thought to have a signaling role contributing to promote apoptosis [121] or to produce the adaptive response to hypoxia [122].

Complex IV, the mitochondrial cytochrome $c$ oxidase (COX), is the terminal oxidase of the mitochondrial respiratory chain: it catalyzes the transfer of electrons from reduced cytochrome $c$ to $\mathrm{O}_{2}$, coupling it to the pumping of protons to the intermembrane space. It is a multimeric enzyme composed of three subunits (COX1-3) conserved from $\alpha$-proteobacteria; these subunits are encoded by the mtDNA and form the catalytic core of the complex [123]. In mammalian cells, up to 11 more subunits encoded by the nuclear genome participate in the COX structure and regulate the enzyme activity to coordinate energy production with the cellular needs [124]. The nuclear encoded subunits present multiple tissue-specific isoforms with slightly different structural features that could impinge on the organization of the holocomplex and on the performance of the enzyme, perhaps helping to meet the different metabolic needs of the different tissues [125, 126]. Impaired COX functioning has consequences on cellular energy metabolism and could result in increased ROS production.

\section{Supercomplexes}

The respiratory chain complexes interact with various stoichiometries to form supercomplexes [127, 128]. The assembly of one unit of complex I, two units of complex III, and one of complex IV is often called the respirasome. The supramolecular association stabilizes individual complex and is thought to increase the efficiency of direct electron transfer from the donor to the acceptor complex by reduction of the diffusion time [129, 130]; it may also decrease the amount of ROS produced during electron transport $[131,132]$; the association between complex I and complex III might contribute to sequestering ubisemiquinone, the reactive ubiquinol intermediate which can react with $\mathrm{O}_{2}$ to generate superoxide.

\section{6. $F_{1}-F_{0}$ ATP Synthase}

The $\mathrm{F}_{1}-\mathrm{F}_{\mathrm{o}}$ ATP synthase is a complex nanomachine that uses the electrochemical proton gradient generated by the respiratory chain to synthesize ATP. It comprises two functional domains: the soluble portion, $\mathrm{F}_{1}$ situated in the matrix, and the $F_{o}$ part embedded in the IMM. $F_{1}$ is composed of three copies of each subunit $\alpha$ and $\beta$, plus one copy of the subunits $\gamma, \delta$, and $\varepsilon$; these last components form the central stalk of the complex. $F_{o}$ consists of 8 copies (in bovine mitochondria) of protein $\mathrm{c}$ forming a ring structure [133]. One copy of each subunit a, b, d, F6, and OSCP 
forms the peripheral stalk which lies on one side of the complex. Additional membrane subunits e, f, g, and A6L are associated with $\mathrm{F}_{\mathrm{o}}[134,135]$. Only subunits a and A6L are encoded by the mitochondrial genome [136]. Protons move through the $\mathrm{F}_{\mathrm{o}}$ complex embedded in the membrane, driving the motion of the rotor composed of the ring of $\mathrm{c}$ subunits and of $\gamma$. The central stalk propagates the momentum to the catalytic $\mathrm{F}_{1}$ subunit where ADP and phosphate react, through a sequence of conformational changes, and $\mathrm{F}_{1}$ catalyzes the synthesis of ATP. When the respiratory chain is impaired or cannot sustain the potential difference across the IMM $(\Delta \psi)$, the $\mathrm{F}_{1} \mathrm{~F}_{\mathrm{o}}$ ATP synthase can work in reverse hydrolyzing ATP and pumping protons from the matrix to the IMS [137]. The ATP synthase associates in dimers via the $\mathrm{F}_{\mathrm{o}}$ portion of the holocomplex $[138,139]$, and the dimers have been shown to form double rows along the crista edges of the IMM. Molecular dynamics simulations suggest that the dimers are able to bend the lipid bilayer and contribute to form the cristae [140]. Recently, a novel function has been proposed for the ATP synthase as the core component of the mitochondrial permeability transition pore (PTP), allowing the regulated opening on the inner membrane of a channel with a molecular cut-off of about $1500 \mathrm{Da}$ [141].

\section{Mitochondrial DNA}

Mitochondria possess their own DNA (mtDNA) with a specific genetic code distinct from the nuclear one. mtDNA is a circular molecule of 16.5 -kilobase $(\mathrm{kb})$ pairs, compacted into DNA-protein supramolecular assemblies called the nucleoids with a diameter of about $100 \mathrm{~nm}$ and present at approximately 1000 copies per cell [142, 143]. At variance from the nuclear DNA, mtDNA has mostly a uniparental inheritance, and for the majority of organisms examined, it is inherited from the female parent [144]. The mtDNA has been reduced during evolution with the transfer of about 99 percent of its genes to the nucleus; it encodes the core genes for bioenergetics: 13 polypeptides of the respiratory chain in complexes I, III, and IV, and in the ATP synthase; two ribosomal RNAs (mt-rRNAs); and 22 transfer RNAs (mt-tRNAs). All these genes are essential for normal mitochondrial function. In addition, there is a noncoding sequence, the displacement loop ( $D$-loop), which comprises the replication origins and promoters for mtDNA. Mitochondria can respond to changes in membrane potential modulating the expression of respiratory chain proteins $[145,146]$.

Respiration rate correlates with the amount of mtDNA in the cells [147], and precise regulation of the mtDNA copy number is necessary for maintaining cellular energy demands: cells with high energy needs, such as neurons and muscle cells, are mostly at risk of energetic failure as a consequence of mtDNA mutation/depletion; in fact, mtDNA depletion or increased degradation has been implicated in human diseases such as Parkinson's [148, 149], Alzheimer's disease $[150,151]$, and aging $[152,153]$. Compared to the nuclear DNA, mtDNA has a much high sequence evolution rate $[154,155]$ that could result in the generation of numerous mutations throughout the life of the cell and the entire organism, and mtDNA variants could influence individual susceptibility to complex diseases $[156,157]$.

\section{Alzheimer's Disease}

Among neurodegenerative disorders, Alzheimer's disease (AD) is the most common form of dementia worldwide [158]; it is characterized by a progressive and fully debilitating decline in cognitive functions. Fundamental neuropathological hallmarks of $\mathrm{AD}$ are the extracellular deposits of insoluble proteins, the plaques, primarily composed of amyloid- $\beta$ (A $\beta)$ peptides, and the intracellular neurofibrillary tangles (NFTs) mainly constituted by phosphorylated microtubule-associated protein tau (Mapt). Compared to nonaffected subjects, tau is abnormally phosphorylated in the brain of $\mathrm{AD}$ patients and this can contribute to its missorting to dendritic filaments and to its polymerization and aggregation [159]. A correspondence is observed between NFT deposition and synapse loss during the course of $\mathrm{AD}$, and each of these processes further correlates with cognitive decline [160].

The large majority of $\mathrm{AD}$ cases are sporadic with age being the single most important risk factor, and the presence of the $\varepsilon 4$ allele of apolipoprotein $\mathrm{E}$ a substantial contributing element [161]. A small, but significant, percentage of cases (between 1 and 5 percent), called collectively familial Alzheimer's disease (FAD), is due to dominant mutations in one of the three genes involved in the synthesis and processing of the amyloid protein. These genes encode for the amyloid precursor protein (APP), presenilin 1 (PS1), and presenilin 2 (PS2), respectively, and the pathological mutations cause an aberrant production of $\mathrm{A} \beta$ peptides: soluble $\mathrm{A} \beta$ peptides of various lengths are thought to be the most pathological forms contributing in the dysfunction and ultimately the demise of neurons. The substantial pathological identity between the sporadic and the familial forms of the disease contributed to the proposition of $\mathrm{A} \beta$ deposition as the central event in the genesis of the disease (the amyloid cascade hypothesis $(\mathrm{ACH}))[162,163]$; though developing, increased knowledge of the disorder posits that this hypothesis falls short of explaining its complete etiology [164]. In fact, the precise origin(s) of the disease is not completely understood, but it is now thought that about 70 percent of the $\mathrm{AD}$ risk is attributable to genetic factors: in fact, a combination of environmental and genetic elements most likely contributes to the disorder though the pathways involved are incompletely understood [165]. Thus, AD appears as a very complex process, perhaps consisting of different interacting phases, characterized by the individual contribution, as well as the interaction, among the different cell types present in the affected brain areas [166].

\section{Obesity}

Obesity is a metabolic disorder that causes an abnormal or excessive fat accumulation that can severely impair health. The fundamental cause of obesity is the energy imbalance between calories consumed and calories expended, as the result of combined increased intake of energy-rich food, 
and the decrease in physical activity. Obesity is a major risk factor for several other diseases such as diabetes and cardiovascular diseases and some types of cancer [167]. It is characterized by low-grade, chronic inflammation [16], an increase in oxidative stress $[168,169]$, and also, mitochondrial dysfunction and altered mitochondrial biogenesis have been frequently observed [170-172]. It is still not known how mitochondrial functioning changes in the adipose tissue in obesity, whether it contributes to the early development of the metabolic alteration and whether it is genetic or acquired, but mitochondrial dysfunction has been implicated in the development of insulin resistance [173-175] which is a common feature in obesity.

\section{Diabetes}

Diabetes comprises an early onset (already in early childhood) disease denominated type 1 caused by the complete failure of the pancreatic islet $\beta$-cell to produce insulin, and it requires exogenous insulin administration for survival; and a chronic, progressive disease denominated type 2 (T2D) characterized by an initial increased insulin secretion leading to islet stress and loss of glucagon/insulin homeostasis. Both disorders present an altered glucose homeostasis that can have serious adverse outcomes compromising brain functions and altering the functionality of peripheral tissues. $\mathrm{T} 2 \mathrm{D}$ is a complex disorder resulting from the interaction between genes and the environment, and several risk factors have been identified ranging from age to sex, diet, and ethnicity. It often associates with obesity and insulin resistance. Genetics is an important factor in the development of T2D, though heritability estimates are quite variable among different studies, from 22 to 69 percent, and might depend on the age of onset $[176,177]$. The challenge is to find genetic markers that explain the increased risk associated with a family history of diabetes. T2D is characterized by an increase in proinflammatory cytokines and chemokines that involves several organs, and the characteristic hyperglycemia results in amyloid deposits that cause increased redox stress for the cells [178].

T2D is considered a protein misfolding disorder associated with the accumulation of islet amyloid polypeptide (IAPP) in pancreatic islets. IAPP, also called amylin, is a peptide hormone cosecreted with insulin from the pancreas. Amylin is elevated in the blood of T2D patients, and misfolded IAPP has been found in the brain of AD patients with T2D [179]; also, $A \beta$ and phosphorylated tau can be found in the pancreas of T2D patients [180]. T2D and impaired fasting glucose represent a comorbidity in about 80 percent of $\mathrm{AD}$ patients [181].

Disease-specific, and common phenotypes among T2D, obesity, and Alzheimer's disease are illustrated in Figure 2.

\section{Association between Obesity, Diabetes, and $A D$}

Several common medical conditions such as heart disease, type 2 diabetes, obesity, and late onset neurodegenerative disorders do not have a single genetic cause: they are likely

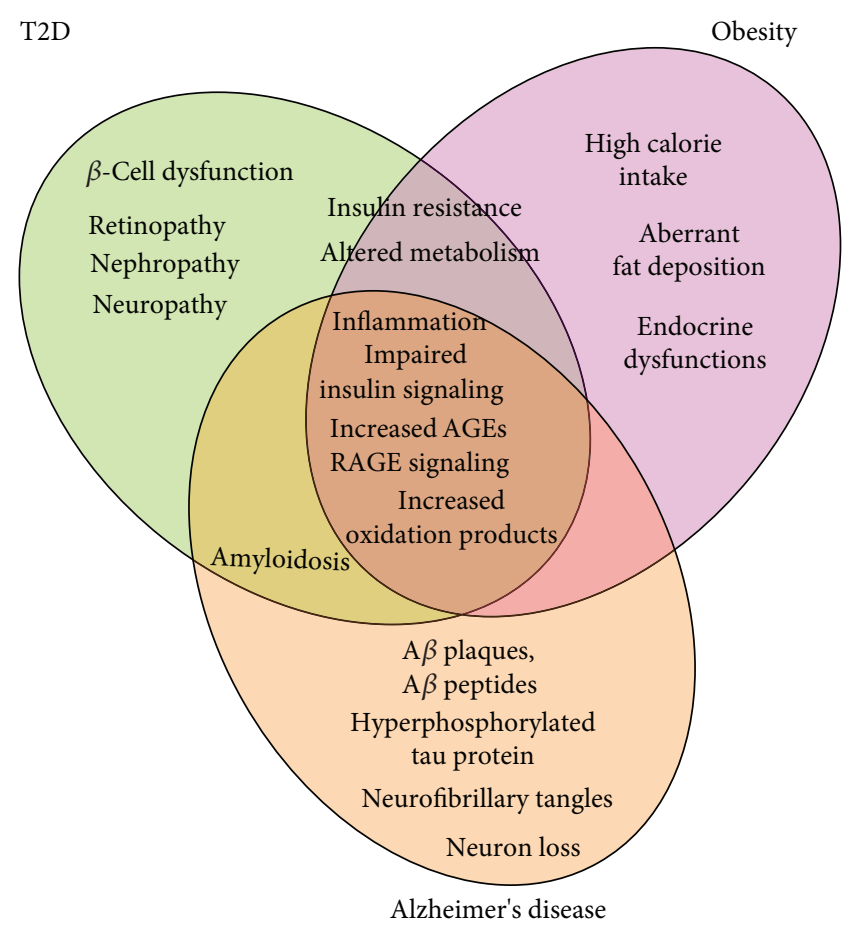

Figure 2: Specific and common features among type 2 diabetes, obesity, and Alzheimer's disease.

associated with the effects of multiple genes (polygenic) in combination with lifestyle and environmental factors. These multifactorial disorders often cluster in families, but do not have a clear pattern of inheritance, and this makes it difficult to determine a person's chance of inheriting or passing on these disorders.

Recently, substantial evidence points to a link between metabolic diseases such as obesity and diabetes and a person's susceptibility to develop Alzheimer's disease. In particular, several longitudinal studies observed an association between a larger waist-hip ratio in middle-age and the increased risk of developing dementia later in life [182] or with a decreased hippocampal volume [183]. Also, a significant relation between obesity in midlife, and the risk of developing dementia later in life has emerged in several epidemiological studies [184-188]. It is worth mentioning, though, that a retrospective cohort study has observed an increased risk of dementia in later life associated with underweight in middle age, questioning the link between obesity and dementia [189]. So these correlations between obesity and dementia are worth more to be studied in order to dissipate discrepancies. High glucose levels have also been found to be a risk factor for dementia, even among people without diabetes [2], and high levels of glycosylated hemoglobin have been associated with lower scores in cognitive function tests [190-192]. A mechanistic link between obesity, diabetes, and dementia could be the low-grade peripheral inflammation, due to chronically elevated levels of circulating free fatty acids, and the development of insulin resistance [193, 194]. Insulin resistance, defined as an insufficient cellular response to a given dose of the hormone, decreases the ability of the cell to preserve energy homeostasis. In the brain, proinflammatory molecules 
TABLE 1: Common risk genes identified in genetic meta-analysis of Alzheimer's disease and in the study of metabolic traits associated with mitochondrial and nuclear mitochondrial variants and genes [38].

\begin{tabular}{lcc}
\hline Gene SNV & Full gene name & SNV \\
\hline WWOX & WW domain-containing oxidoreductase & rs4752856 \\
MTCH2 & Mitochondrial carrier 2 & Expression regulated by MTCH2 rs4752856 \\
PSMC3 & Proteasome 26S subunit, ATPase 3 & Expression regulated by MTCH2 rs3817335 \\
C1QTNF4 & C1q and TNF-related 4 & Expression regulated by MTCH2 rs7118178 \\
CELF1 & CUGBP Elav-like family member 1 & Expression regulated by NR1H3 rs7120118 \\
ACP2 & Acid phosphatase 2, lysosomal
\end{tabular}

such as TNF $\alpha$ released from activated microglia were found to contribute to impaired insulin signaling and synapse loss via aberrant activation of JNK signaling that in turn causes a decreased activation of PI3-kinase and Akt proteins with consequences for cellular growth and increased susceptibility to apoptosis.

Increased inflammatory signaling leads also to an increase in ROS production. In the brain, controlled ROS production is involved in synaptic signaling and mechanisms related to long-term potentiation and memory consolidation [195]; an imbalance between ROS production and antioxidant defenses [196] could lead to oxidative stress and increased amounts of oxidized lipids, proteins, and nucleic acids [197]. In fact, in the AD brain, an augmented ROS production occurs together with suppressed mitochondrial fast axonal transport, [198] fragmentation of neuronal mitochondria and impaired mitochondrial dynamics at synapses [199].

A subtle but chronic impairment in energy production could also develop in neurodegeneration later in life. More recently, an early developing metabolic defect impinging most likely on glycolysis and resulting, as a cascade effect, also on mitochondria energy production with a significant decrease in $\mathrm{NAD}(\mathrm{P}) \mathrm{H}$ concentration has been observed in a mouse model of familial AD disease bearing a mutated form of human PS2 and mutated human APP [200].

\section{Mitochondria and Metabolic Disorders}

Mitochondria might not be simply the subjects on which altered metabolism impinges causing their malfunctioning but could also be principal actors conditioning the cellular/organismal response to the environment. Dysregulated mitochondrial $\mathrm{Ca}^{2+}$ signaling and $\mathrm{Ca}^{2+}$ homeostasis are involved in the pathogenesis of insulin insensitivity and T2D [201], and altered ER mitochondrial $\mathrm{Ca}^{2+}$ signaling is a crucial aspect in the impairments produced by the mutated PS 2 protein that can have a major role in the development of neurodegeneration in FAD cases [202, 203].

The presence in the cell of two distinct genomes implies that the nucleus and mitochondria must coordinate transcription and translation and also the translocation of mitochondrial proteins [204]. The nucleus controls mitochondrial functions through so-called "anterograde regulation," modulating mitochondrial activity and promoting mitochondrial biogenesis to meet the cellular needs. Conversely, mitochondria signal to the nucleus the need to modify nuclear gene expression for adaptive cellular responses via "retrograde response" [205]. Miscommunication between the nucleus and mitochondria can have important consequences for the cell; defects in the regulation/expression of several mitochondrial proteins have been associated with metabolic phenotypes in animal models and in humans. Altered functioning of several mitochondrial chaperones HSP60, HSP90, and HSP72 has resulted closely associated with insulin resistance, obesity, and type 2 diabetes, both in animal models and in humans [206-208]. Mitochondria also possess an array of conserved proteases important for quality control: the LON protease (LONP1) degrades oxidized proteins within the matrix, and a reduced expression has been associated with chronic stress, aging, and age-related disorders [209]. The protease presenilin-associated rhomboid-like (PARL) regulates oxidative phosphorylation in skeletal muscle and insulin signaling; knockdown of PARL causes malformation of the cristae, increases oxidative stress, and impairs insulin signaling [210].

The mitochondrial genome itself has been shown to deeply influence several aspects of physiology ranging from insulin signaling and obesity to telomere shortening and median lifespan: mtDNA haplotypes, nonpathological mitochondrial DNA variants, appear to have a broad effect on metabolism, and the differences observed seem to be more pronounced later in life [211].

The dual genomic origin of mitochondrial components, from mtDNA and nDNA, with the former subjected to a high mutational rate $[154,155]$ prompted the hypothesis that mitochondrial variants influence individual susceptibility to complex diseases $[156,157]$. In particular, human mtDNA presents large sequence variability within populations, and many studies have suggested that mtDNA variants may be associated with ageing or diseases. Moreover, a generalized, systemic energy defect could in fact result in organ-specific symptoms since mitochondrial dysfunctions affect the cellular energy balance [212], and energy demands differ between different cell types and different organs.

A recent study has associated mitochondrial and nuclear mitochondrial variants with seven metabolic traits ranging from body mass index (BMI) and glycosylated hemoglobin (HbA1c) to fasting glucose and insulin [38]. The study examined risk factors involved mainly in cardiovascular disease, but traits have emerged linked to some neurodegenerative disorders and in particular to Alzheimer's disease. In fact, a number of these variants are also found among the risk genes for Alzheimer's disease discovered by genetic meta-analysis of clinically diagnosed late-onset 
Alzheimer's disease [213]; common risk genes are summarized in Table 1.

\section{Conclusions}

A growing body of data points to a close relationship between metabolic disorders such as obesity, diabetes, and neurodegeneration. Moreover, altered mitochondrial functions emerge in all those diseases. Perhaps, this comes not as a surprise given the numerous, important functions sustained by the mitochondria in the cell: in particular the production of energy necessary for all cellular functions and also the release of signaling molecules in response to external stimuli. All these aspects are worth investigating for a better insight of chronic and debilitating disorders that do not have a univocal etiology and that are affecting an ever-increasing number of people worldwide. In particular, a deeper understanding of the interaction of a specific mtDNA haplotype and the environment could provide the development of preventative strategies to delay or hopefully block the progression of the disorders.

\section{Disclosure}

Giulia Rigotto's present address is Immunology and Molecular Oncology, Veneto Institute of Oncology (IOV-IRCCS), 35128, Padua. This work is in partial fulfillment of the requirements for the $\mathrm{PhD}$ degree of Giulia Rigotto.

\section{Conflicts of Interest}

The authors declare no competing financial interests.

\section{Acknowledgments}

Emy Basso is supported by the Italian National Research Council (CNR). This work was supported by Fondazione Telethon Grant N.GGP16029A 0017, Fondazione Cariparo Progetti di Eccellenza 2017 “GliAD” project 2018/0113, and Euro-BioImaging project to Tullio Pozzan.

\section{References}

[1] L. D. Baker, D. J. Cross, S. Minoshima, D. Belongia, G. S. Watson, and S. Craft, "Insulin resistance and Alzheimerlike reductions in regional cerebral glucose metabolism for cognitively normal adults with prediabetes or early type 2 diabetes," Archives of Neurology, vol. 68, no. 1, pp. 51-57, 2011.

[2] R. K. Roul and S. K. Sahay, "K-means and Wordnet based feature selection combined with extreme learning machines for text classification," in Distributed Computing and Internet Technology, N. Bjørner, S. Prasad, and L. Parida, Eds., vol. 9581, pp. 103-112, Springer, Cham, 2016.

[3] K. Talbot, H.-Y. Wang, H. Kazi et al., "Demonstrated brain insulin resistance in Alzheimer's disease patients is associated with IGF-1 resistance, IRS-1 dysregulation, and cognitive decline," Journal of Clinical Investigation, vol. 122, no. 4, pp. 1316-1338, 2012.

[4] S. E. Arnold, Z. Arvanitakis, S. L. Macauley-Rambach et al., "Brain insulin resistance in type 2 diabetes and Alzheimer disease: concepts and conundrums," Nature Reviews Neurology, vol. 14, no. 3, pp. 168-181, 2018.

[5] G. T. Dodd, N. J. Michael, R. S. Lee-Young et al., "Insulin regulates POMC neuronal plasticity to control glucose metabolism," eLife, vol. 7, 2018.

[6] Q. Wan, Z. G. Xiong, H. Y. Man et al., "Recruitment of functional $\mathrm{GABA}_{\mathrm{A}}$ receptors to postsynaptic domains by insulin," Nature, vol. 388, no. 6643, pp. 686-690, 1997.

[7] R. Takechi, M. M. Pallebage-Gamarallage, V. Lam, C. Giles, and J. C. Mamo, "Aging-related changes in blood-brain barrier integrity and the effect of dietary fat," Neurodegenerative Diseases, vol. 12, no. 3, pp. 125-135, 2013.

[8] R. Takechi, V. Lam, E. Brook et al., "Blood-brain barrier dysfunction precedes cognitive decline and neurodegeneration in diabetic insulin resistant mouse model: an implication for causal link," Frontiers in Aging Neuroscience, vol. 9, 2017.

[9] M. C. Thomas, J. M. Forbes, and M. E. Cooper, "Advanced glycation end products and diabetic nephropathy," American Journal of Therapeutics, vol. 12, no. 6, pp. 562-572, 2005.

[10] P. Salahuddin, G. Rabbani, and R. Khan, "The role of advanced glycation end products in various types of neurodegenerative disease: a therapeutic approach," Cellular and Molecular Biology Letters, vol. 19, no. 3, pp. 407-437, 2014.

[11] J. Li, D. Liu, L. Sun, Y. Lu, and Z. Zhang, “Advanced glycation end products and neurodegenerative diseases: mechanisms and perspective," Journal of the Neurological Sciences, vol. 317 , no. $1-2$, pp. 1-5, 2012.

[12] B. Franko, J. Brault, T. Jouve et al., "Differential impact of glucose levels and advanced glycation end-products on tubular cell viability and pro-inflammatory/profibrotic functions," Biochemical and Biophysical Research Communications, vol. 451, no. 4, pp. 627-631, 2014.

[13] Z. Cai, N. Liu, C. Wang et al., "Role of RAGE in Alzheimer's disease," Cellular and Molecular Neurobiology, vol. 36, no. 4, pp. 483-495, 2016.

[14] R. Park, S.-Y. Kook, J.-C. Park, and I. Mook-Jung, "A $\beta_{1-42}$ reduces $\mathrm{P}$-glycoprotein in the blood-brain barrier through RAGE-NF- $\kappa \mathrm{B}$ signaling," Cell Death \& Disease, vol. 5, no. 6, article e1299, 2014.

[15] J. G. Neels and J. M. Olefsky, "Inflamed fat: what starts the fire?," Journal of Clinical Investigation, vol. 116, no. 1, pp. 33-35, 2006.

[16] M. Mraz and M. Haluzik, "The role of adipose tissue immune cells in obesity and low-grade inflammation," The Journal of Endocrinology, vol. 222, no. 3, pp. R113-R127, 2014.

[17] C. J. Shu, C. Benoist, and D. Mathis, "The immune system's involvement in obesity-driven type 2 diabetes," Seminars in Immunology, vol. 24, no. 6, pp. 436-442, 2012.

[18] A. D. Pradhan, J. E. Manson, N. Rifai, J. E. Buring, and P. M. Ridker, "C-reactive protein, interleukin 6, and risk of developing type 2 diabetes mellitus," Journal of the American Medical Association, vol. 286, no. 3, pp. 327-334, 2001.

[19] D. Cai and T. Liu, "Inflammatory cause of metabolic syndrome via brain stress and NF- $\kappa \mathrm{B}$," Aging, vol. 4, no. 2, pp. 98-115, 2012.

[20] M. T. Heneka, M. P. Kummer, and E. Latz, "Innate immune activation in neurodegenerative disease," Nature Reviews Immunology, vol. 14, no. 7, pp. 463-477, 2014.

[21] B. Zhang, C. Gaiteri, L.-G. Bodea et al., "Integrated systems approach identifies genetic nodes and networks in late-onset Alzheimer's disease," Cell, vol. 153, no. 3, pp. 707-720, 2013. 
[22] A. C. Naj, G. Jun, G. W. Beecham et al., "Common variants at MS4A4/MS4A6E, CD2AP, CD33 and EPHA1 are associated with late-onset Alzheimer's disease," Nature Genetics, vol. 43, no. 5, pp. 436-441, 2011.

[23] P. Hollingworth, D. Harold, R. Sims et al., "Common variants at $A B C A 7, M S 4 A 6 A / M S 4 A 4 E, E P H A 1, C D 33$ and $C D 2 A P$ are associated with Alzheimer's disease," Nature Genetics, vol. 43, no. 5, pp. 429-435, 2011.

[24] F. G. De Felice and S. T. Ferreira, "Inflammation, defective insulin signaling, and mitochondrial dysfunction as common molecular denominators connecting type 2 diabetes to Alzheimer disease," Diabetes, vol. 63, no. 7, pp. 2262-2272, 2014.

[25] S. Vyas, E. Zaganjor, and M. C. Haigis, "Mitochondria and cancer," Cell, vol. 166, no. 3, pp. 555-566, 2016.

[26] B. DuBoff, J. Götz, and M. B. Feany, "Tau promotes neurodegeneration via DRP1 mislocalization in vivo," Neuron, vol. 75, no. 4, pp. 618-632, 2012.

[27] M. P. Murphy and R. C. Hartley, "Mitochondria as a therapeutic target for common pathologies," Nature Reviews Drug Discovery, vol. 17, no. 12, pp. 865-886, 2018.

[28] C. M. Kusminski and P. E. Scherer, "Mitochondrial dysfunction in white adipose tissue," Trends in Endocrinology \& Metabolism, vol. 23, no. 9, pp. 435-443, 2012.

[29] S. Boudina and T. E. Graham, "Mitochondrial function/dysfunction in white adipose tissue," Experimental Physiology, vol. 99, no. 9, pp. 1168-1178, 2014.

[30] M. Liesa and O. S. Shirihai, "Mitochondrial dynamics in the regulation of nutrient utilization and energy expenditure," Cell Metabolism, vol. 17, no. 4, pp. 491-506, 2013.

[31] A. Zorzano, M. Liesa, and M. Palacín, "Role of mitochondrial dynamics proteins in the pathophysiology of obesity and type 2 diabetes," The International Journal of Biochemistry \& Cell Biology, vol. 41, no. 10, pp. 1846-1854, 2009.

[32] R. Putti, R. Sica, V. Migliaccio, and L. Lionetti, "Diet impact on mitochondrial bioenergetics and dynamics," Frontiers in Physiology, vol. 6, 2015.

[33] L. M. Hinder, C. Figueroa-Romero, C. Pacut et al., "Long-chain acyl coenzyme A synthetase 1 overexpression in primary cultured Schwann cells prevents long chain fatty acid-induced oxidative stress and mitochondrial dysfunction," Antioxidants \& Redox Signaling, vol. 21, no. 4, pp. 588-600, 2014.

[34] N. Krako, M. C. Magnifico, M. Arese et al., "Characterization of mitochondrial dysfunction in the 7PA2 cell model of Alzheimer's disease," Journal of Alzheimer's Disease, vol. 37, no. 4, pp. 747-758, 2013.

[35] J. Chow, J. Rahman, J. C. Achermann, M. T. Dattani, and S. Rahman, "Mitochondrial disease and endocrine dysfunction," Nature Reviews Endocrinology, vol. 13, no. 2, pp. 92-104, 2017.

[36] J. L. Saben, A. L. Boudoures, Z. Asghar et al., "Maternal metabolic syndrome programs mitochondrial dysfunction via germline changes across three generations," Cell Reports, vol. 16, no. 1, pp. 1-8, 2016.

[37] A. P. West and G. S. Shadel, "Mitochondrial DNA in innate immune responses and inflammatory pathology," Nature Reviews Immunology, vol. 17, no. 6, pp. 363-375, 2017.

[38] A. T. Kraja, C. Liu, J. L. Fetterman et al., "Associations of mitochondrial and nuclear mitochondrial variants and genes with seven metabolic traits," American Journal of Human Genetics, vol. 104, no. 1, pp. 112-138, 2019.
[39] I. E. Wallin, "Bacteria and the origin of species," Science, vol. 64 , no. 1651 , pp. 173-175, 1926.

[40] L. Sagan, "On the origin of mitosing cells," Journal of Theoretical Biology, vol. 14, no. 3, pp. 225-274, 1967.

[41] A. Papazoglou and V. Ferrari, "Fast object segmentation in unconstrained video," in 2013 IEEE International Conference on Computer Vision, pp. 1777-1784, Sydney, NSW, Australia, December 2013.

[42] M. W. Gray, G. Burger, and B. F. Lang, "Mitochondrial evolution," Science, vol. 283, no. 5407, pp. 1476-1481, 1999.

[43] T. Cavalier-Smith, "Predation and eukaryote cell origins: a coevolutionary perspective," The International Journal of Biochemistry \& Cell Biology, vol. 41, no. 2, pp. 307-322, 2009.

[44] C. de Duve, "The origin of eukaryotes: a reappraisal," Nature Reviews Genetics, vol. 8, no. 5, pp. 395-403, 2007.

[45] N. Lane and W. Martin, "The energetics of genome complexity,” Nature, vol. 467, no. 7318, pp. 929-934, 2010.

[46] M. W. Gray, B. F. Lang, and G. Burger, "Mitochondria of protists," Annual Review of Genetics, vol. 38, no. 1, pp. 477-524, 2004.

[47] D. C. Wallace, "Mitochondria as chi," Genetics, vol. 179, no. 2, pp. 727-735, 2008.

[48] R. Recchioni, F. Marcheselli, F. Moroni, and C. Pieri, “Apoptosis in human aortic endothelial cells induced by hyperglycemic condition involves mitochondrial depolarization and is prevented by $N$-acetyl-L-cysteine," Metabolism, vol. 51, no. 11, pp. 1384-1388, 2002.

[49] M. Barry, J. Heibein, M. Pinkoski, and R. C. Bleackley, "Quantitative measurement of apoptosis induced by cytotoxic T lymphocytes," Methods in Enzymology, vol. 322, pp. 40-46, 2000.

[50] J. F. Strauss III, T. Kishida, L. K. Christenson, T. Fujimoto, and H. Hiroi, "START domain proteins and the intracellular trafficking of cholesterol in steroidogenic cells," Molecular and Cellular Endocrinology, vol. 202, no. 1-2, pp. 59-65, 2003.

[51] W. L. Miller, "Steroid hormone synthesis in mitochondria," Molecular and Cellular Endocrinology, vol. 379, no. 1-2, pp. 62-73, 2013.

[52] G. Daum and J. E. Vance, "Import of lipids into mitochondria," Progress in Lipid Research, vol. 36, no. 2-3, pp. 103-130, 1997.

[53] C. Osman, D. R. Voelker, and T. Langer, "Making heads or tails of phospholipids in mitochondria," The Journal of Cell Biology, vol. 192, no. 1, pp. 7-16, 2011.

[54] E. Zinser, C. D. Sperka-Gottlieb, E. V. Fasch, S. D. Kohlwein, F. Paltauf, and G. Daum, "Phospholipid synthesis and lipid composition of subcellular membranes in the unicellular eukaryote Saccharomyces cerevisiae," Journal of Bacteriology, vol. 173, no. 6, pp. 2026-2034, 1991.

[55] G. Tuller, T. Nemec, C. Hrastnik, and G. Daum, "Lipid composition of subcellular membranes of an FY1679-derived haploid yeast wild-type strain grown on different carbon sources," Yeast, vol. 15, no. 14, pp. 1555-1564, 1999.

[56] C. D. M. Sperka-Gottlieb, A. Hermetter, F. Paltauf, and G. Daum, "Lipid topology and physical properties of the outer mitochondrial membrane of the yeast, Saccharomyces cerevisiae," Biochimica et Biophysica Acta (BBA) - Biomembranes, vol. 946, no. 2, pp. 227-234, 1988.

[57] J. S. Harb, J. Comte, and D. C. Gautheron, "Asymmetrical orientation of phospholipids and their interactions with marker enzymes in pig heart mitochondrial inner 
membrane," Archives of Biochemistry and Biophysics, vol. 208, no. 1, pp. 305-318, 1981.

[58] D. Cheneval, M. Muller, R. Toni, S. Ruetz, and E. Carafoli, "Adriamycin as a probe for the transversal distribution of cardiolipin in the inner mitochondrial membrane," The Journal of Biological Chemistry, vol. 260, no. 24, pp. 13003-13007, 1985.

[59] R. Hovius, J. Thijssen, P. van der Linden, K. Nicolay, and B. de Kruijff, "Phospholipid asymmetry of the outer membrane of rat liver mitochondria," FEBS Letters, vol. 330, no. 1, pp. 71-76, 1993.

[60] C. T. Schwall, V. L. Greenwood, and N. N. Alder, "The stability and activity of respiratory complex II is cardiolipin-dependent," Biochimica et Biophysica Acta (BBA) Bioenergetics, vol. 1817, no. 9, pp. 1588-1596, 2012.

[61] F. Jiang, M. T. Ryan, M. Schlame et al., "Absence of cardiolipin in the $\mathrm{crd} 1$ null mutant results in decreased mitochondrial membrane potential and reduced mitochondrial function," The Journal of Biological Chemistry, vol. 275, no. 29, pp. 22387-22394, 2000.

[62] M. Zhang, E. Mileykovskaya, and W. Dowhan, "Gluing the respiratory chain together," The Journal of Biological Chemistry, vol. 277, no. 46, pp. 43553-43556, 2002.

[63] K. Pfeiffer, V. Gohil, R. A. Stuart et al., "Cardiolipin stabilizes respiratory chain supercomplexes," The Journal of Biological Chemistry, vol. 278, no. 52, pp. 52873-52880, 2003.

[64] K. D. Hauff and G. M. Hatch, "Cardiolipin metabolism and Barth syndrome," Progress in Lipid Research, vol. 45, no. 2, pp. 91-101, 2006.

[65] M. Schlame and M. Ren, "Barth syndrome, a human disorder of cardiolipin metabolism," FEBS Letters, vol. 580, no. 23, pp. 5450-5455, 2006.

[66] R. M. DeVay, L. Dominguez-Ramirez, L. L. Lackner, S. Hoppins, H. Stahlberg, and J. Nunnari, "Coassembly of Mgm1 isoforms requires cardiolipin and mediates mitochondrial inner membrane fusion," The Journal of Cell Biology, vol. 186, no. 6, pp. 793-803, 2009.

[67] T. Ban, T. Ishihara, H. Kohno et al., "Molecular basis of selective mitochondrial fusion by heterotypic action between OPA1 and cardiolipin," Nature Cell Biology, vol. 19, no. 7, pp. 856-863, 2017.

[68] I. Bustillo-Zabalbeitia, S. Montessuit, E. Raemy, G. Basañez, O. Terrones, and J.-C. Martinou, "Specific interaction with cardiolipin triggers functional activation of dynamin-related protein 1," PLoS One, vol. 9, no. 7, article e102738, 2014.

[69] C. A. Francy, R. W. Clinton, C. Fröhlich, C. Murphy, and J. A. Mears, "Cryo-EM studies of Drp1 reveal cardiolipin interactions that activate the helical oligomer," Scientific Reports, vol. 7, no. 1, article 10744, 2017.

[70] C. T. Chu, J. Ji, R. K. Dagda et al., "Cardiolipin externalization to the outer mitochondrial membrane acts as an elimination signal for mitophagy in neuronal cells," Nature Cell Biology, vol. 15, no. 10, pp. 1197-1205, 2013.

[71] C. T. Chu, H. Bayır, and V. E. Kagan, "LC3 binds externalized cardiolipin on injured mitochondria to signal mitophagy in neurons," Autophagy, vol. 10, no. 2, pp. 376-378, 2013.

[72] S. Y. Noskov, T. K. Rostovtseva, A. C. Chamberlin, O. Teijido, W. Jiang, and S. M. Bezrukov, "Current state of theoretical and experimental studies of the voltage-dependent anion channel (VDAC)," Biochimica et Biophysica Acta (BBA) Biomembranes, vol. 1858, no. 7, pp. 1778-1790, 2016.
[73] O. Schmidt, N. Pfanner, and C. Meisinger, "Mitochondrial protein import: from proteomics to functional mechanisms," Nature Reviews Molecular Cell Biology, vol. 11, no. 9, pp. 655667, 2010.

[74] T. Endo and K. Yamano, "Transport of proteins across or into the mitochondrial outer membrane," Biochimica et Biophysica Acta (BBA) - Molecular Cell Research, vol. 1803, no. 6, pp. 706-714, 2010.

[75] S. Kutik, D. Stojanovski, L. Becker et al., "Dissecting membrane insertion of mitochondrial $\beta$-barrel proteins," Cell, vol. 132, no. 6, pp. 1011-1024, 2008.

[76] A. I. C. Höhr, C. Lindau, C. Wirth et al., "Membrane protein insertion through a mitochondrial $\beta$-barrel gate," Science, vol. 359, no. 6373, article eaah6834, 2018.

[77] C. Meisinger, M. Rissler, A. Chacinska et al., "The mitochondrial morphology protein Mdm10 functions in assembly of the preprotein translocase of the outer membrane," Developmental Cell, vol. 7, no. 1, pp. 61-71, 2004.

[78] N. Flinner, L. Ellenrieder, S. B. Stiller, T. Becker, E. Schleiff, and O. Mirus, "Mdm10 is an ancient eukaryotic porin cooccurring with the ERMES complex," Biochimica et Biophysica Acta (BBA) - Molecular Cell Research, vol. 1833, no. 12, pp. 3314-3325, 2013.

[79] L. Ellenrieder, Ł. Opaliński, L. Becker et al., "Separating mitochondrial protein assembly and endoplasmic reticulum tethering by selective coupling of Mdm10," Nature Communications, vol. 7, no. 1, 2016.

[80] V. Krüger, T. Becker, L. Becker et al., "Identification of new channels by systematic analysis of the mitochondrial outer membrane," The Journal of Cell Biology, vol. 216, no. 11, pp. 3485-3495, 2017.

[81] T. G. Frey and C. A. Mannella, "The internal structure of mitochondria," Trends in Biochemical Sciences, vol. 25, no. 7, pp. 319-324, 2000.

[82] C. A. Wurm and S. Jakobs, "Differential protein distributions define two sub-compartments of the mitochondrial inner membrane in yeast," FEBS Letters, vol. 580, no. 24, pp. 5628-5634, 2006.

[83] S. De La Fuente, C. Fernandez-Sanz, C. Vail et al., "Strategic positioning and biased activity of the mitochondrial calcium uniporter in cardiac muscle," The Journal of Biological Chemistry, vol. 291, no. 44, pp. 23343-23362, 2016.

[84] A. Chacinska, C. M. Koehler, D. Milenkovic, T. Lithgow, and N. Pfanner, "Importing mitochondrial proteins: machineries and mechanisms," Cell, vol. 138, no. 4, pp. 628-644, 2009.

[85] R. Quintana-Cabrera, A. Mehrotra, G. Rigoni, and M. E. Soriano, "Who and how in the regulation of mitochondrial cristae shape and function," Biochemical and Biophysical Research Communications, vol. 500, no. 1, pp. 94-101, 2018.

[86] C. A. Mannella, "Structure and dynamics of the mitochondrial inner membrane cristae," Biochimica et Biophysica Acta (BBA) - Molecular Cell Research, vol. 1763, no. 5-6, pp. 542-548, 2006.

[87] H. M. Heath-Engel and G. C. Shore, "Mitochondrial membrane dynamics, cristae remodelling and apoptosis," Biochimica et Biophysica Acta (BBA) - Molecular Cell Research, vol. 1763, no. 5-6, pp. 549-560, 2006.

[88] G. Perkins, C. Renken, M. E. Martone, S. J. Young, M. Ellisman, and T. Frey, "Electron tomography of neuronal mitochondria: three-dimensional structure and organization 
of cristae and membrane contacts," Journal of Structural Biology, vol. 119, no. 3, pp. 260-272, 1997.

[89] C. A. Mannella, M. Marko, P. Penczek, D. Barnard, and J. Frank, "The internal compartmentation of rat-liver mitochondria: tomographic study using the high-voltage transmission electron microscope," Microscopy Research and Technique, vol. 27, no. 4, pp. 278-283, 1994.

[90] D. Nicastro, A. S. Frangakis, D. Typke, and W. Baumeister, "Cryo-electron tomography of neurospora mitochondria," Journal of Structural Biology, vol. 129, no. 1, pp. 48-56, 2000.

[91] J. Xie, M. F. Marusich, P. Souda, J. Whitelegge, and R. A. Capaldi, "The mitochondrial inner membrane protein Mitofilin exists as a complex with SAM50, metaxins 1 and 2 , coiled-coil-helix coiled-coil-helix domain-containing protein 3 and 6 and DnaJC11," FEBS Letters, vol. 581, no. 18, pp. 3545-3549, 2007.

[92] C. Ding, Z. Wu, L. Huang et al., "Mitofilin and CHCHD6 physically interact with Sam50 to sustain cristae structure," Scientific Reports, vol. 5, no. 1, article 16064, 2015.

[93] M. Bohnert, R. M. Zerbes, K. M. Davies et al., "Central role of Mic10 in the mitochondrial contact site and cristae organizing system," Cell Metabolism, vol. 21, no. 5, pp. 747-755, 2015.

[94] M. Barbot, D. C. Jans, C. Schulz et al., "Mic10 Oligomerizes to bend mitochondrial inner membranes at cristae junctions," Cell Metabolism, vol. 21, no. 5, pp. 756-763, 2015.

[95] F.-N. Vögtle, J. M. Burkhart, S. Rao et al., "Intermembrane space proteome of yeast mitochondria," Molecular \& Cellular Proteomics, vol. 11, no. 12, pp. 1840-1852, 2012.

[96] A. M. Porcelli, A. Ghelli, C. Zanna, P. Pinton, R. Rizzuto, and M. Rugolo, " $\mathrm{pH}$ difference across the outer mitochondrial membrane measured with a green fluorescent protein mutant," Biochemical and Biophysical Research Communications, vol. 326, no. 4, pp. 799-804, 2005.

[97] J. Hu, L. Dong, and C. E. Outten, "The redox environment in the mitochondrial intermembrane space is maintained separately from the cytosol and matrix," Journal of Biological Chemistry, vol. 283, no. 43, pp. 29126-29134, 2008.

[98] J. M. Herrmann and J. Riemer, "The intermembrane space of mitochondria," Antioxidants \& Redox Signaling, vol. 13, no. 9, pp. 1341-1358, 2010.

[99] H. Martin, C. Eckerskorn, F. Gärtner, J. Rassow, F. Lottspeich, and N. Pfanner, "The yeast mitochondrial intermembrane space: purification and analysis of two distinct fractions," Analytical Biochemistry, vol. 265, no. 1, pp. 123-128, 1998.

[100] F. Vogel, C. Bornhövd, W. Neupert, and A. S. Reichert, "Dynamic subcompartmentalization of the mitochondrial inner membrane," The Journal of Cell Biology, vol. 175, no. 2, pp. 237-247, 2006.

[101] L. Scorrano, M. Ashiya, K. Buttle et al., "A distinct pathway remodels mitochondrial cristae and mobilizes cytochrome $c$ during apoptosis," Developmental Cell, vol. 2, no. 1, pp. 55-67, 2002.

[102] C. Frezza, S. Cipolat, O. Martins de Brito et al., "OPA1 controls apoptotic cristae remodeling independently from mitochondrial fusion," Cell, vol. 126, no. 1, pp. 177-189, 2006.

[103] J. Llopis, J. M. McCaffery, A. Miyawaki, M. G. Farquhar, and R. Y. Tsien, "Measurement of cytosolic, mitochondrial, and Golgi $\mathrm{pH}$ in single living cells with green fluorescent proteins," Proceedings of the National Academy of Sciences of the United States of America, vol. 95, no. 12, pp. 6803-6808, 1998.

[104] J. Carroll, R. J. Shannon, I. M. Fearnley, J. E. Walker, and J. Hirst, "Definition of the nuclear encoded protein composition of bovine heart mitochondrial complex I: identification of two new subunits," Journal of Biological Chemistry, vol. 277, no. 52, pp. 50311-50317, 2002.

[105] K. Fiedorczuk, J. A. Letts, G. Degliesposti, K. Kaszuba, M. Skehel, and L. A. Sazanov, "Atomic structure of the entire mammalian mitochondrial complex I," Nature, vol. 538, no. 7625, pp. 406-410, 2016.

[106] J. Zhu, K. R. Vinothkumar, and J. Hirst, "Structure of mammalian respiratory complex I," Nature, vol. 536, no. 7616, pp. 354-358, 2016.

[107] G. Ambrosio, J. L. Zweier, C. Duilio et al., "Evidence that mitochondrial respiration is a source of potentially toxic oxygen free radicals in intact rabbit hearts subjected to ischemia and reflow," Journal of Biological Chemistry, vol. 268, no. 25, pp. 18532-18541, 1993.

[108] A. B. Kotlyar and A. D. Vinogradov, "Slow active/inactive transition of the mitochondrial NADH-ubiquinone reductase," Biochimica et Biophysica Acta (BBA) - Bioenergetics, vol. 1019, no. 2, pp. 151-158, 1990.

[109] I. S. Gostimskaya, G. Cecchini, and A. D. Vinogradov, "Topography and chemical reactivity of the active-inactive transition-sensitive SH-group in the mitochondrial NADH:ubiquinone oxidoreductase (complex I)," Biochimica et Biophysica Acta (BBA) - Bioenergetics, vol. 1757, no. 9-10, pp. 1155-1161, 2006.

[110] P. G. Roberts and J. Hirst, "The deactive form of respiratory complex I from mammalian mitochondria is a $\mathrm{Na}^{+} / \mathrm{H}^{+}$antiporter," Journal of Biological Chemistry, vol. 287, no. 41, pp. 34743-34751, 2012.

[111] E. T. Chouchani, V. R. Pell, E. Gaude et al., "Ischaemic accumulation of succinate controls reperfusion injury through mitochondrial ROS," Nature, vol. 515, no. 7527, pp. 431-435, 2014.

[112] G. Burger, B. F. Lang, M. Reith, and M. W. Gray, "Genes encoding the same three subunits of respiratory complex II are present in the mitochondrial DNA of two phylogenetically distant eukaryotes," Proceedings of the National Academy of Sciences of the United States of America, vol. 93, no. 6, pp. 2328-2332, 1996.

[113] F. Sun, X. Huo, Y. Zhai et al., "Crystal structure of mitochondrial respiratory membrane protein complex II," Cell, vol. 121, no. 7, pp. 1043-1057, 2005.

[114] A. K. Nath, J. H. Ryu, Y. N. Jin et al., "PTPMT1 Inhibition lowers glucose through succinate dehydrogenase phosphorylation," Cell Reports, vol. 10, no. 5, pp. 694-701, 2015.

[115] J. Favier, L. Amar, and A.-P. Gimenez-Roqueplo, "Paraganglioma and phaeochromocytoma: from genetics to personalized medicine," Nature Reviews Endocrinology, vol. 11, no. 2, pp. 101-111, 2015.

[116] J. Finsterer, "Leigh and Leigh-like syndrome in children and adults," Pediatric Neurology, vol. 39, no. 4, pp. 223-235, 2008.

[117] X. H. Yang and B. L. Trumpower, "Purification of a threesubunit ubiquinol-cytochrome c oxidoreductase complex from Paracoccus denitrificans," Journal of Biological Chemistry, vol. 261, no. 26, pp. 12282-12289, 1986. 
[118] D. Xia, C. A. Yu, H. Kim et al., "Crystal structure of the cytochrome $\mathrm{bc}_{1}$ complex from bovine heart mitochondria," Science, vol. 277, no. 5322, pp. 60-66, 1997.

[119] C. Lange and C. Hunte, "Crystal structure of the yeast cytochrome $b c_{1}$ complex with its bound substrate cytochrome $c$," Proceedings of the National Academy of Sciences of the United States of America, vol. 99, no. 5, pp. 2800-2805, 2002.

[120] F. L. Muller, Y. Liu, and H. Van Remmen, "Complex III releases superoxide to both sides of the inner mitochondrial membrane," Journal of Biological Chemistry, vol. 279, no. 47, pp. 49064-49073, 2004.

[121] S. Soberanes, D. Urich, C. M. Baker et al., "Mitochondrial complex III-generated oxidants activate ASK1 and JNK to induce alveolar epithelial cell death following exposure to particulate matter air pollution," Journal of Biological Chemistry, vol. 284, no. 4, pp. 2176-2186, 2009.

[122] L. Bleier and S. Dröse, "Superoxide generation by complex III: From mechanistic rationales to functional consequences," Biochimica et Biophysica Acta (BBA) - Bioenergetics, vol. 1827, no. 11-12, pp. 1320-1331, 2013.

[123] A. Timón-Gómez, E. Nývltová, L. A. Abriata, A. J. Vila, J. Hosler, and A. Barrientos, "Mitochondrial cytochrome c oxidase biogenesis: recent developments," Seminars in Cell \& Developmental Biology, vol. 76, pp. 163-178, 2018.

[124] D. Pierron, D. E. Wildman, M. Hüttemann, G. C. Markondapatnaikuni, S. Aras, and L. I. Grossman, "Cytochrome $c$ oxidase: evolution of control via nuclear subunit addition," Biochimica et Biophysica Acta (BBA) - Bioenergetics, vol. 1817, no. 4, pp. 590-597, 2012.

[125] M. Hüttemann, S. Helling, T. H. Sanderson et al., "Regulation of mitochondrial respiration and apoptosis through cell signaling: cytochrome $c$ oxidase and cytochrome $c$ in ischemia/reperfusion injury and inflammation," Biochimica et Biophysica Acta (BBA) - Bioenergetics, vol. 1817, no. 4, pp. 598-609, 2012.

[126] B. Kadenbach and M. Hüttemann, "The subunit composition and function of mammalian cytochrome $c$ oxidase," Mitochondrion, vol. 24, pp. 64-76, 2015.

[127] R. Acín-Pérez, M.. P. Bayona-Bafaluy, P. Fernández-Silva et al., "Respiratory complex III is required to maintain complex I in mammalian mitochondria," Molecular Cell, vol. 13, no. 6, pp. 805-815, 2004.

[128] F. Diaz, H. Fukui, S. Garcia, and C. T. Moraes, "Cytochrome $c$ oxidase is required for the assembly/stability of respiratory complex I in mouse fibroblasts," Molecular and Cellular Biology, vol. 26, no. 13, pp. 4872-4881, 2006.

[129] C. Bianchi, M. L. Genova, G. Parenti Castelli, and G. Lenaz, "The mitochondrial respiratory chain is partially organized in a supercomplex assembly: kinetic evidence using flux control analysis," Journal of Biological Chemistry, vol. 279, no. 35, pp. 36562-36569, 2004.

[130] H. Schägger and K. Pfeiffer, "Supercomplexes in the respiratory chains of yeast and mammalian mitochondria," The EMBO Journal, vol. 19, no. 8, pp. 1777-1783, 2000.

[131] E. Maranzana, G. Barbero, A. I. Falasca, G. Lenaz, and M. L. Genova, "Mitochondrial respiratory supercomplex association limits production of reactive oxygen species from complex I," Antioxidants \& Redox Signaling, vol. 19, no. 13, pp. 1469-1480, 2013.

[132] I. Lopez-Fabuel, J. le Douce, A. Logan et al., "Complex I assembly into supercomplexes determines differential mitochondrial ROS production in neurons and astrocytes," Proceedings of the National Academy of Sciences of the United States of America, vol. 113, no. 46, pp. 13063-13068, 2016.

[133] I. Wittig and H. Schägger, "Structural organization of mitochondrial ATP synthase," Biochimica et Biophysica Acta (BBA) - Bioenergetics, vol. 1777, no. 7-8, pp. 592-598, 2008.

[134] J. E. Walker and V. K. Dickson, "The peripheral stalk of the mitochondrial ATP synthase," Biochimica et Biophysica Acta (BBA) - Bioenergetics, vol. 1757, no. 5-6, pp. 286-296, 2006.

[135] R. J. Devenish, M. Prescott, and A. J. W. Rodgers, "The structure and function of mitochondrial $\mathrm{F}_{1} \mathrm{~F}_{0}$-ATP synthases," International Review of Cell and Molecular Biology, vol. 267, pp. 1-58, 2008.

[136] S. Anderson, A. T. Bankier, B. G. Barrell et al., "Sequence and organization of the human mitochondrial genome," Nature, vol. 290, no. 5806, pp. 457-465, 1981.

[137] I. Husain and D. A. Harris, "ATP synthesis and hydrolysis in submitochondrial particles subjected to an acid-base transition," FEBS Letters, vol. 160, no. 1-2, pp. 110-114, 1983.

[138] I. Arnold, K. Pfeiffer, W. Neupert, R. A. Stuart, and H. Schägger, "Yeast mitochondrial $\mathrm{F}_{1} \mathrm{~F}_{0}$-ATP synthase exists as a dimer: identification of three dimer-specific subunits," The EMBO Journal, vol. 17, no. 24, pp. 7170-7178, 1998.

[139] G. Arselin, M. F. Giraud, A. Dautant et al., "The GxxxG motif of the transmembrane domain of subunit $\mathrm{e}$ is involved in the dimerization/oligomerization of the yeast ATP synthase complex in the mitochondrial membrane," European Journal of Biochemistry, vol. 270, no. 8, pp. 1875-1884, 2003.

[140] K. M. Davies, C. Anselmi, I. Wittig, J. D. Faraldo-Gomez, and W. Kuhlbrandt, "Structure of the yeast $\mathrm{F}_{1} \mathrm{~F}_{\mathrm{o}}$-ATP synthase dimer and its role in shaping the mitochondrial cristae," Proceedings of the National Academy of Sciences of the United States of America, vol. 109, no. 34, pp. 13602-13607, 2012.

[141] V. Giorgio, S. von Stockum, M. Antoniel et al., "Dimers of mitochondrial ATP synthase form the permeability transition pore," Proceedings of the National Academy of Sciences of the United States of America, vol. 110, no. 15, pp. 58875892, 2013.

[142] C. Kukat, C. A. Wurm, H. Spahr, M. Falkenberg, N.-G. Larsson, and S. Jakobs, "Super-resolution microscopy reveals that mammalian mitochondrial nucleoids have a uniform size and frequently contain a single copy of mtDNA," Proceedings of the National Academy of Sciences of the United States of America, vol. 108, no. 33, pp. 13534-13539, 2011.

[143] D. Bogenhagen and D. A. Clayton, "The number of mitochondrial deoxyribonucleic acid genomes in mouse $\mathrm{L}$ and human HeLa cells: Quantitative isolation of mitochondrial deoxyribonucleic acid," Journal of Biological Chemistry, vol. 249, no. 24, pp. 7991-7995, 1974.

[144] R. E. Giles, H. Blanc, H. M. Cann, and D. C. Wallace, "Maternal inheritance of human mitochondrial DNA," Proceedings of the National Academy of Sciences of the United States of America, vol. 77, no. 11, pp. 6715-6719, 1980.

[145] J. F. Allen, "Control of gene expression by redox potential and the requirement for chloroplast and mitochondrial genomes," Journal of Theoretical Biology, vol. 165, no. 4, pp. 609-631, 1993.

[146] J. F. Allen, "The function of genomes in bioenergetic organelles," Philosophical Transactions of the Royal Society of London. Series B: Biological Sciences, vol. 358, no. 1429, pp. 19-38, 2003. 
[147] C. Rocher, J. W. Taanman, D. Pierron et al., "Influence of mitochondrial DNA level on cellular energy metabolism: implications for mitochondrial diseases," Journal of Bioenergetics and Biomembranes, vol. 40, no. 2, pp. 59-67, 2008.

[148] R. K. Dagda, J. Zhu, S. M. Kulich, and C. T. Chu, "Mitochondrially localized ERK2 regulates mitophagy and autophagic cell stress," Autophagy, vol. 4, no. 6, pp. 770-782, 2008.

[149] A. Grünewald, K. A. Rygiel, P. D. Hepplewhite, C. M. Morris, M. Picard, and D. M. Turnbull, "Mitochondrial DNA depletion in respiratory chain-deficient Parkinson disease neurons," Annals of Neurology, vol. 79, no. 3, pp. 366-378, 2016.

[150] K. J. Krishnan, T. E. Ratnaike, H. L. M. De Gruyter, E. Jaros, and D. M. Turnbull, "Mitochondrial DNA deletions cause the biochemical defect observed in Alzheimer's disease," Neurobiology of Aging, vol. 33, no. 9, pp. 2210-2214, 2012.

[151] M. Corral-Debrinski, T. Horton, M. T. Lott et al., "Marked changes in mitochondrial DNA deletion levels in Alzheimer brains," Genomics, vol. 23, no. 2, pp. 471-476, 1994.

[152] K. A. Laderman, J. R. Penny, F. Mazzucchelli, N. Bresolin, G. Scarlato, and G. Attardi, "Aging-dependent functional alterations of mitochondrial DNA (mtDNA) from human fibroblasts transferred into mtDNA-less cells," Journal of Biological Chemistry, vol. 271, no. 27, pp. 15891-15897, 1996.

[153] K. Foote, J. Reinhold, E. P. K. Yu et al., "Restoring mitochondrial DNA copy number preserves mitochondrial function and delays vascular aging in mice," Aging Cell, vol. 17, no. 4, article e12773, 2018.

[154] C. Haag-Liautard, N. Coffey, D. Houle, M. Lynch, B. Charlesworth, and P. D. Keightley, "Direct estimation of the mitochondrial DNA mutation rate in Drosophila melanogaster," PLoS Biology, vol. 6, no. 8, article e204, 2008.

[155] M. Neiman and D. R. Taylor, "The causes of mutation accumulation in mitochondrial genomes," Proceedings of the Royal Society B: Biological Sciences, vol. 276, no. 1660, pp. 1201-1209, 2009.

[156] L. Craven, C. L. Alston, R. W. Taylor, and D. M. Turnbull, "Recent Advances in mitochondrial disease," Annual Review of Genomics and Human Genetics, vol. 18, no. 1, pp. 257-275, 2017.

[157] A. M. Schaefer, M. Walker, D. M. Turnbull, and R. W. Taylor, "Endocrine disorders in mitochondrial disease," Molecular and Cellular Endocrinology, vol. 379, no. 1-2, pp. 2-11, 2013.

[158] C. P. Ferri, M. Prince, C. Brayne et al., "Global prevalence of dementia: a Delphi consensus study," The Lancet, vol. 366, no. 9503, pp. 2112-2117, 2005.

[159] C. Despres, C. Byrne, H. Qi et al., "Identification of the Tau phosphorylation pattern that drives its aggregation," Proceedings of the National Academy of Sciences of the United States of America, vol. 114, no. 34, pp. 9080-9085, 2017.

[160] H. Zempel and E. Mandelkow, "Lost after translation: missorting of Tau protein and consequences for Alzheimer disease," Trends in Neurosciences, vol. 37, no. 12, pp. 721-732, 2014.

[161] P. B. Verghese, J. M. Castellano, and D. M. Holtzman, "Apolipoprotein E in Alzheimer's disease and other neurological disorders," The Lancet Neurology, vol. 10, no. 3, pp. 241-252, 2011.

[162] C. L. Masters and K. Beyreuther, “Alzheimer's disease: molecular basis of structural lesions," Brain Pathology, vol. 1, no. 4, pp. 226-227, 1991.
[163] J. Hardy and D. Allsop, "Amyloid deposition as the central event in the aetiology of Alzheimer's disease," Trends in Pharmacological Sciences, vol. 12, no. 10, pp. 383-388, 1991.

[164] E. Karran and B. De Strooper, "The amyloid cascade hypothesis: are we poised for success or failure?," Journal of Neurochemistry, vol. 139, pp. 237-252, 2016.

[165] C. Reitz, C. Brayne, and R. Mayeux, "Epidemiology of Alzheimer disease," Nature Reviews Neurology, vol. 7, no. 3, pp. 137-152, 2011.

[166] B. De Strooper and E. Karran, "The cellular phase of Alzheimer's disease," Cell, vol. 164, no. 4, pp. 603-615, 2016.

[167] J. A. Knight, "Diseases and disorders associated with excess body weight," Annals of Clinical \& Laboratory Science, vol. 41, no. 2, pp. 107-121, 2011.

[168] S. A. Noeman, H. E. Hamooda, and A. A. Baalash, "Biochemical study of oxidative stress markers in the liver, kidney and heart of high fat diet induced obesity in rats," Diabetology \& Metabolic Syndrome, vol. 3, no. 1, p. 17, 2011.

[169] M. Matsuda and I. Shimomura, "Increased oxidative stress in obesity: Implications for metabolic syndrome, diabetes, hypertension, dyslipidemia, atherosclerosis, and cancer," Obesity Research \& Clinical Practice, vol. 7, no. 5, pp. e330-e341, 2013.

[170] S. Heinonen, J. Buzkova, M. Muniandy et al., "Impaired mitochondrial biogenesis in adipose tissue in acquired obesity," Diabetes, vol. 64, no. 9, pp. 3135-3145, 2015.

[171] A. De Pauw, S. Tejerina, M. Raes, J. Keijer, and T. Arnould, "Mitochondrial (dys)function in adipocyte (de)differentiation and systemic metabolic alterations," The American Journal of Pathology, vol. 175, no. 3, pp. 927-939, 2009.

[172] S. Altshuler-Keylin and S. Kajimura, "Mitochondrial homeostasis in adipose tissue remodeling," Science Signaling, vol. 10, no. 468, p. eaai9248, 2017.

[173] M. K. Montgomery and N. Turner, "Mitochondrial dysfunction and insulin resistance: an update," Endocrine Connections, vol. 4, no. 1, pp. R1-15, 2015.

[174] C. Vernochet, F. Damilano, A. Mourier et al., "Adipose tissue mitochondrial dysfunction triggers a lipodystrophic syndrome with insulin resistance, hepatosteatosis, and cardiovascular complications," The FASEB Journal, vol. 28, no. 10, pp. 4408-4419, 2014.

[175] P. Wiklund, X. Zhang, S. Pekkala et al., "Insulin resistance is associated with altered amino acid metabolism and adipose tissue dysfunction in normoglycemic women," Scientific Reports, vol. 6, no. 1, article 24540, 2016.

[176] P. Almgren, M. Lehtovirta, B. Isomaa et al., "Heritability and familiality of type 2 diabetes and related quantitative traits in the Botnia Study," Diabetologia, vol. 54, no. 11, pp. 2811-2819, 2011.

[177] A. Mahajan, D. Taliun, M. Thurner et al., "Fine-mapping type 2 diabetes loci to single-variant resolution using highdensity imputation and islet-specific epigenome maps," Nature Genetics, vol. 50, no. 11, pp. 1505-1513, 2018.

[178] A. Abedini and A. M. Schmidt, "Mechanisms of islet amyloidosis toxicity in type 2 diabetes," FEBS Letters, vol. 587, no. 8, pp. 1119-1127, 2013.

[179] K. Jackson, G. A. Barisone, E. Diaz, L. Jin, C. DeCarli, and F. Despa, "Amylin deposition in the brain: a second amyloid in Alzheimer disease?," Annals of Neurology, vol. 74, no. 4, pp. 517-526, 2013. 
[180] J. Miklossy, H. Qing, A. Radenovic et al., "Beta amyloid and hyperphosphorylated tau deposits in the pancreas in type 2 diabetes," Neurobiology of Aging, vol. 31, no. 9, pp. 1503-1515, 2010.

[181] Z. Chen and C. Zhong, “Decoding Alzheimer's disease from perturbed cerebral glucose metabolism: implications for diagnostic and therapeutic strategies," Progress in Neurobiology, vol. 108, pp. 21-43, 2013.

[182] R. A. Whitmer, D. R. Gustafson, E. Barrett-Connor, M. N. Haan, E. P. Gunderson, and K. Yaffe, "Central obesity and increased risk of dementia more than three decades later," Neurology, vol. 71, no. 14, pp. 1057-1064, 2008.

[183] W. Jagust, D. Harvey, D. Mungas, and M. Haan, "Central obesity and the aging brain," Archives of Neurology, vol. 62, no. 10 , pp. $1545-1548,2005$.

[184] A. L. Fitzpatrick, L. H. Kuller, O. L. Lopez et al., "Midlife and late-life obesity and the risk of dementia: Cardiovascular Health Study," Archives of Neurology, vol. 66, no. 3, pp. 336-342, 2009.

[185] L. B. Hassing, A. K. Dahl, V. Thorvaldsson et al., "Overweight in midlife and risk of dementia: a 40-year follow-up study," International Journal of Obesity, vol. 33, no. 8, pp. 893-898, 2009.

[186] L. B. Hassing, A. K. Dahl, N. L. Pedersen, and B. Johansson, "Overweight in midlife is related to lower cognitive function 30 years later: a prospective study with longitudinal assessments," Dementia and Geriatric Cognitive Disorders, vol. 29, no. 6, pp. 543-552, 2010 .

[187] R. A. Whitmer, E. P. Gunderson, E. Barrett-Connor, C. P. Quesenberry Jr, and K. Yaffe, "Obesity in middle age and future risk of dementia: a 27 year longitudinal population based study," BMJ, vol. 330, no. 7504, article 1360, 2005.

[188] W. L. Xu, A. R. Atti, M. Gatz, N. L. Pedersen, B. Johansson, and L. Fratiglioni, "Midlife overweight and obesity increase late-life dementia risk: a population-based twin study," Neurology, vol. 76, no. 18, pp. 1568-1574, 2011.

[189] N. Qizilbash, J. Gregson, M. E. Johnson et al., "BMI and risk of dementia in two million people over two decades: a retrospective cohort study," The Lancet Diabetes \& Endocrinology, vol. 3, no. 6, pp. 431-436, 2015.

[190] L. Kerti, A. V. Witte, A. Winkler, U. Grittner, D. Rujescu, and A. Floel, "Higher glucose levels associated with lower memory and reduced hippocampal microstructure," Neurology, vol. 81, no. 20, pp. 1746-1752, 2013.

[191] J. R. Marden, E. R. Mayeda, E. J. Tchetgen Tchetgen, I. Kawachi, and M. M. Glymour, "High hemoglobin Alc and diabetes predict memory decline in the health and retirement study," Alzheimer Disease \& Associated Disorders, vol. 31, no. 1, pp. 48-54, 2017.

[192] C. Pappas, B. J. Small, R. Andel et al., "Blood glucose levels may exacerbate executive function deficits in older adults with cognitive impairment," Journal of Alzheimer's Disease, vol. 67, no. 1, pp. 81-89, 2019.

[193] X. Lei, M. M. Seldin, H. C. Little, N. Choy, T. Klonisch, and G. W. Wong, "C1q/TNF-related protein 6 (CTRP6) links obesity to adipose tissue inflammation and insulin resistance," Journal of Biological Chemistry, vol. 292, no. 36, pp. 14836-14850, 2017.

[194] F. Naznin, K. Toshinai, T. M. Z. Waise et al., "Diet-induced obesity causes peripheral and central ghrelin resistance by promoting inflammation," Journal of Endocrinology, vol. 226, no. 1, pp. 81-92, 2015.

[195] F. Serrano and E. Klann, "Reactive oxygen species and synaptic plasticity in the aging hippocampus," Ageing Research Reviews, vol. 3, no. 4, pp. 431-443, 2004.

[196] M.-H. Yoo, X. Gu, X. M. Xu et al., "Delineating the role of glutathione peroxidase 4 in protecting cells against lipid hydroperoxide damage and in Alzheimer's disease," Antioxidants \& Redox Signaling, vol. 12, no. 7, pp. 819-827, 2010.

[197] L. J. McIntosh, M. A. Trush, and J. C. Troncoso, "Increased susceptibility of Alzheimer's disease temporal cortex to oxygen free radical-mediated processes," Free Radical Biology and Medicine, vol. 23, no. 2, pp. 183-190, 1997.

[198] J. Riemer and S. Kins, "Axonal transport and mitochondrial dysfunction in Alzheimer's disease," Neurodegenerative Diseases, vol. 12, no. 3, pp. 111-124, 2013.

[199] P. H. Reddy, X. Yin, M. Manczak et al., "Mutant APP and amyloid beta-induced defective autophagy, mitophagy, mitochondrial structural and functional changes and synaptic damage in hippocampal neurons from Alzheimer's disease," Human Molecular Genetics, vol. 27, no. 14, pp. 2502-2516, 2018.

[200] P. Theurey, N. M. C. Connolly, I. Fortunati et al., "Systems biology identifies preserved integrity but impaired metabolism of mitochondria due to a glycolytic defect in Alzheimer's disease neurons," Aging Cell, vol. 18, no. 3, article e12924, 2019.

[201] C.-H. Wang and Y.-H. Wei, "Role of mitochondrial dysfunction and dysregulation of $\mathrm{Ca}^{2+}$ homeostasis in the pathophysiology of insulin resistance and type 2 diabetes," Journal of Biomedical Science, vol. 24, no. 1, p. 70, 2017.

[202] S. Sarasija, J. T. Laboy, Z. Ashkavand, J. Bonner, Y. Tang, and K. R. Norman, "Presenilin mutations deregulate mitochondrial $\mathrm{Ca}^{2+}$ homeostasis and metabolic activity causing neurodegeneration in Caenorhabditis elegans," eLife, vol. 7, 2018.

[203] E. Zampese, C. Fasolato, M. J. Kipanyula, M. Bortolozzi, T. Pozzan, and P. Pizzo, "Presenilin 2 modulates endoplasmic reticulum (ER)-mitochondria interactions and $\mathrm{Ca}^{2+}$ crosstalk," Proceedings of the National Academy of Sciences of the United States of America, vol. 108, no. 7, pp. 2777-2782, 2011.

[204] D. J. Pagliarini, S. E. Calvo, B. Chang et al., "A mitochondrial protein compendium elucidates complex I disease biology," Cell, vol. 134, no. 1, pp. 112-123, 2008.

[205] P. M. Quirós, A. Mottis, and J. Auwerx, "Mitonuclear communication in homeostasis and stress," Nature Reviews Molecular Cell Biology, vol. 17, no. 4, pp. 213-226, 2016.

[206] A. Kleinridders, H. P. M. M. Lauritzen, S. Ussar et al., "Leptin regulation of $H s p 60$ impacts hypothalamic insulin signaling," Journal of Clinical Investigation, vol. 123, no. 11, pp. 46674680, 2013.

[207] I. Lazaro, A. Oguiza, C. Recio et al., "Targeting HSP90 ameliorates nephropathy and atherosclerosis through suppression of NF- $\kappa$ B and STAT signaling pathways in diabetic mice," Diabetes, vol. 64, no. 10, pp. 3600-3613, 2015.

[208] D. C. Henstridge, C. R. Bruce, B. G. Drew et al., "Activating HSP72 in rodent skeletal muscle increases mitochondrial number and oxidative capacity and decreases insulin resistance," Diabetes, vol. 63, no. 6, pp. 1881-1894, 2014.

[209] J. K. Ngo, L. C. D. Pomatto, D. A. Bota, A. L. Koop, and K. J. A. Davies, "Impairment of lon-induced protection against the accumulation of oxidized proteins in senescent $\mathrm{Wi}-38$ 
fibroblasts," The Journals of Gerontology Series A: Biological Sciences and Medical Sciences, vol. 66A, no. 11, pp. 1178-1185, 2011.

[210] A. E. Civitarese, P. S. MacLean, S. Carling et al., "Regulation of skeletal muscle oxidative capacity and insulin signaling by the mitochondrial rhomboid protease PARL," Cell Metabolism, vol. 11, no. 5, pp. 412-426, 2010.

[211] A. Latorre-Pellicer, R. Moreno-Loshuertos, A. V. LechugaVieco et al., "Mitochondrial and nuclear DNA matching shapes metabolism and healthy ageing," Nature, vol. 535, no. 7613, pp. 561-565, 2016.

[212] D. C. Wallace, "Bioenergetic origins of complexity and disease," Cold Spring Harbor Symposia on Quantitative Biology, vol. 76, pp. 1-16, 2011.

[213] B. W. Kunkle, Alzheimer Disease Genetics Consortium (ADGC), B. Grenier-Boley et al., "Genetic meta-analysis of diagnosed Alzheimer's disease identifies new risk loci and implicates $\mathrm{A} \beta$, tau, immunity and lipid processing," Nature Genetics, vol. 51, no. 3, pp. 414-430, 2019. 


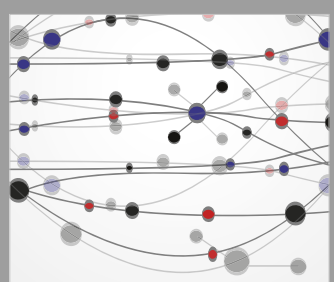

The Scientific World Journal
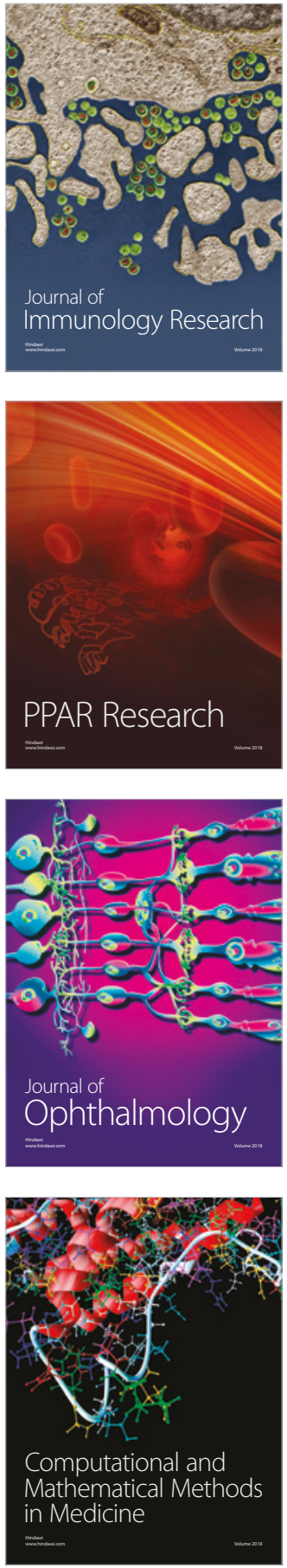

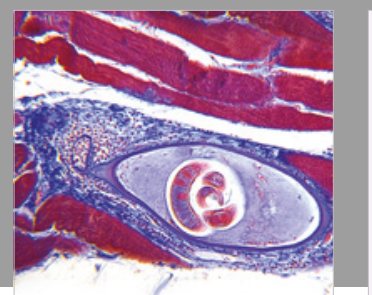

Gastroenterology Research and Practice

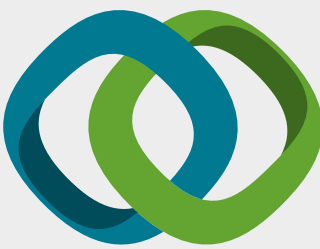

\section{Hindawi}

Submit your manuscripts at

www.hindawi.com
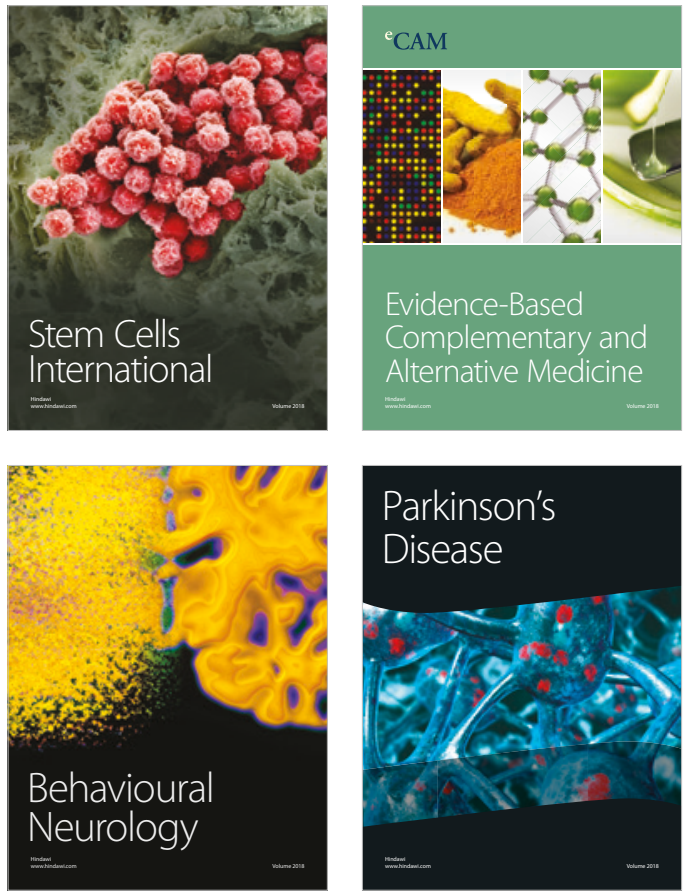

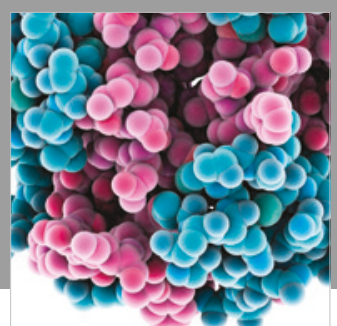

ournal of

Diabetes Research

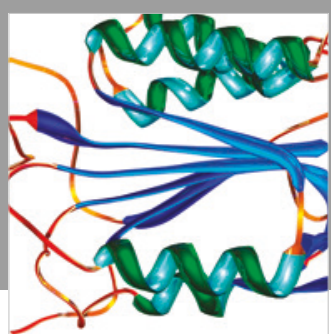

Disease Markers
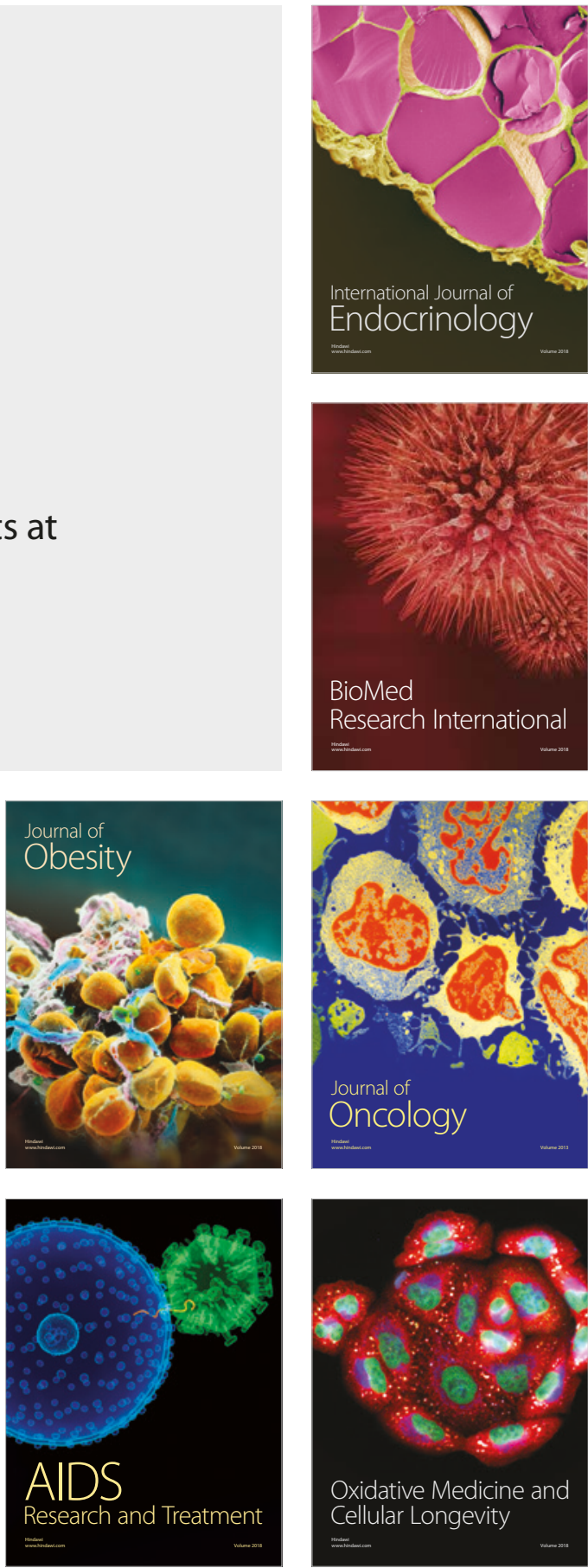